\title{
Evaluation of Various Starchy Foods: A Systematic Review and Meta-Analysis on Chemical Properties Affecting the Glycemic Index Values Based on In Vitro and In Vivo Experiments
}

\author{
Frendy Ahmad Afandi ${ }^{1,2,+}{ }^{\mathbb{D}}$, Christofora Hanny Wijaya ${ }^{1}\left(\mathbb{D}\right.$, Didah Nur Faridah ${ }^{1, *,+}$, Nugraha Edhi Suyatma $^{1}$ \\ and Anuraga Jayanegara $3,+(\mathbb{D}$ \\ 1 Department of Food Science and Technology, IPB University, Bogor 16880, Indonesia; \\ frendy_afandi@apps.ipb.ac.id (F.A.A.); channywijaya@apps.ipb.ac.id (C.H.W.); \\ nugrahaedhis@gmail.com (N.E.S.) \\ 2 Deputy Ministry for Food and Agribusiness, Coordinating Ministry for Economic Affairs \\ Republic of Indonesia, Jakarta 10710, Indonesia \\ 3 Department of Animal Nutrition and Feed Technology, IPB University, Bogor 16880, Indonesia; \\ anuraga.jayanegara@gmail.com \\ * Correspondence: didah_nf@apps.ipb.ac.id \\ + These authors contributed equally to this work.
}

Citation: Afandi, F.A.; Wijaya, C.H.; Faridah, D.N.; Suyatma, N.E.;

Jayanegara, A. Evaluation of Various Starchy Foods: A Systematic Review and Meta-Analysis on Chemical Properties Affecting the Glycemic Index Values Based on In Vitro and In Vivo Experiments. Foods 2021, 10, 364 https://doi.org/10.3390/foods10020364

Academic Editor: Charles Brennan

Received: 9 January 2021

Accepted: 2 February 2021

Published: 8 February 202

Publisher's Note: MDPI stays neutral with regard to jurisdictional claims in published maps and institutional affiliations.

Copyright: (c) 2021 by the authors. Licensee MDPI, Basel, Switzerland. This article is an open access article distributed under the terms and conditions of the Creative Commons Attribution (CC BY) license (https:/ creativecommons.org/licenses/by/ $4.0 /)$
Abstract: The chemical properties that serve as major determinants for the glycemic index (GI) of starchy food and recommended low-GI, carbohydrate-based foods have remained enigmatic. This present work performed a systematic assessment of linkages between chemical properties of foods and GI, and selected low-GI starchy foods. The data were sourced from literature published in various scientific journals. In total, 57 relevant studies and 936 data points were integrated into a database. Both in vitro and in vivo studies on GI values were included. The database was subsequently subjected to a meta-analysis. Meta-analysis from in vitro studies revealed that the two significant factors responsible for the GI of starchy foods were resistant starch and phenolic content (respectively, standardized mean difference (SMD): $-2.52,95 \%$ confidence interval $(95 \% \mathrm{CI})$ : -3.29 to $-1.75, p$ ( $p$-value) $<0.001$; SMD: $-0.72,95 \% \mathrm{CI}:-1.26$ to $-0.17, p=0.005)$, while the lowestGI crop type was legumes. Subgroup analysis restricted to the crop species with significant low GI found two crops, i.e., sorghum (SMD: $-0.69,95 \% \mathrm{CI}$ : -2.33 to $0.96, p<0.001$ ) and red kidney bean (SMD: $-0.39,95 \% \mathrm{CI}$ : -2.37 to $1.59, p=0.001$ ). Meta-analysis from in vivo studies revealed that the two significant factors responsible for the GI of starchy foods were flavonoid and phenolic content (respectively, SMD: $-0.67,95 \% \mathrm{CI}:-0.87$ to $-0.47, p<0.001$; SMD: $-0.63,95 \% \mathrm{CI}:-1.15$ to $-0.11, p=0.009$ ), while the lowest-GI crop type was fruit (banana). In conclusion, resistant starch and phenolic content may have a desirable impact on the GI of starchy food, while sorghum and red kidney bean are found to have low GI.

Keywords: bioactive compounds; carbohydrate foods; diabetes; glycemic index; meta-analysis

\section{Introduction}

Type 1 diabetes mellitus (T1DM) has become a chronic metabolic disorder worldwide, and the regulation of blood glucose at a near-normal level could best fit the goals of preventing or delaying long-term diabetes complications in T1DM [1]. Insulin treatment alone is inadequate for controlling T1DM; essentially, dietary adjustments are required for the proper regulation of blood glucose level. In addition to type 1 diabetes mellitus, the glycemic index is associated with other non-communicable diseases such as cardiovascular diseases (CVDs), type 2 diabetes, and cancer [2]. Glycemic index (GI) is defined as the blood glucose response measured as the area under the curve (AUC) in response to a test food that an individual consumes under standard conditions and is expressed as a percentage of the AUC following consumption of a reference food that the same individual 
consumes on a different day [1]. A GI classification system is in common use. In this system, foods are categorized as having low $(\leq 55)$, medium $(55<\mathrm{GI} \leq 70)$, or high GI $(>70)$ [2] Carbohydrates are among the major determinants of postprandial blood glucose and are directly related to the GI. Accordingly, there is a crucial need for information regarding the relationship between various starchy foods and their GI properties. Such information would allow consumers to appropriately adjust their foods based on the GI profile [3,4]. Further, elucidating the chemical properties of starchy foods responsible for GI is essential. These chemical properties can be relevant indicators for selecting foods with low GI [5]. However, the relationship between the chemical properties of starchy foods and GI is not thoroughly known.

Evidence from randomized controlled trials (RCTs) was reported to be inconsistent [4,6,7], while no report was found using systematic review [8] or meta-analysis [9]. Furthermore, five recent trials [10-14] with adequate power have been published and involved new evidence. Therefore, we performed this meta-analysis to explain the chemical property factors affecting the GI of starchy foods and selected low-GI carbohydrate foods.

\section{Materials and Methods}

\subsection{Literature Search}

This research referred to the guidelines of a meta-analysis handbook [15]. Relevant studies published in various scientific journals and indexed in electronic databases such as PubMed, Proquest, Science Direct, Cengage Library, and Google Scholar were identified, focusing on the relationship between food chemical properties and GI values.

Keywords used in the search strategy included "chemical properties", "glycemic index", "carbohydrate category", and/or "blood glucose response". After examining the titles and abstracts, we excluded irrelevant studies. Subsequently, we examined the full texts of all remaining articles to determine eligibility. The discrepancies were verified by discussion and consensus. We also reviewed the identified trials and review articles in reference lists to find any other potential proper reports.

This systematic review and meta-analysis were based on the PRISMA (Preferred Reporting Items for Systematic Reviews and Meta-Analyses statement) checklist. Each section and each subsection should be clearly identified. The search strategy used in the electronic databases employed keywords, inclusion criteria, and exclusion criteria. The keywords that were used in this research were: available carbohydrate, glycemic index, blood glucose, diabetic, weight management, and hypoglycemic. Among those keywords, only glycemic index was detected in the MeSH (Medical Subject Headings) database. The inclusion criteria were the following: peer-reviewed, clinical trial, completely randomized design, in vitro, in vivo, within the last 20 years. Exclusion criteria were the following: letters to the editor, proceedings, abstracts, and book chapters.

\subsection{Eligibility Criteria}

The eligibility of the trials was determined according to the following criteria: (1) design: completely randomized design that analyzed the relationships between food chemical properties and GI values; (2) population: all research that applied both in vitro and in vivo protocols for determining GI; (3) intervention: comparison between chemical properties, GI value, and selected low-GI carbohydrate-based foods; and (4) data: sufficient information (data) for calculating the standardized mean difference (SMD) and the corresponding 95\% confidence interval (CI). Further, all published papers were written in English.

\subsection{Data Extraction}

Data from each included study were extracted and integrated into the database. The following data were collected: authors, year of publication, country of origin, number of patients or participants, intervention, control, sample/type, method/reference food, outcomes data (GI value), and follow-up. 


\subsection{Risk of Bias Assessment}

To assess the risk of bias, Cochrane risk of bias tool was employed [16]. This was performed by using the following criteria: allocation concealment; random sequence generation; participants and personnel blinding; outcome assessment blinding; selective reporting; incomplete outcome data; and other bias. Each study was evaluated and scored as having "high", "low", or "unclear" risk of bias. Patient and clinician blinding was highly difficult and generally not feasible in these tests, and we determined that the main outcome was less vulnerable to being affected by lack of blinding. Consequently, studies with a high risk of bias for any one (or more) of the key domains were considered to have a high risk of bias. Studies for all key domains except blinding were considered to have a low risk of bias; otherwise, studies were considered to have an unclear risk of bias [17].

\subsection{Quality of Evidence Assessment}

The quality of evidence for primary and secondary outcomes was evaluated according to GRADE (Grading of Recommendations, Assessment, Development, and Evaluation) procedure for risk of bias, inconsistency, indirectness, imprecision, and publication bias, which were categorized as high, moderate, low, or very low [18]. The results were then summarized in tables constructed using the GRADE system [18-20] (GRADE version 3.6) (Table 1). Stages of the study, including literature search, data extraction, risk of bias assessment, and evidence grade assessment were performed independently by one author (Frendy Ahmad Afandi/FAA).

\subsection{Statistical Analysis}

We used weighted analysis using Hedges' d (Standard Mean Difference/SMD) for statistical methods. The data extracted from selected journals were mean, standard deviation or standard error, and the number of replicate experiments. The SMD with corresponding $95 \% \mathrm{CI}$ values were pooled using the random-effects model. Exploration of heterogeneity across studies was carried out using the $\mathrm{I}^{2}$ index [20] (the $\mathrm{I}^{2}>50 \%$ indicated sufficient heterogeneity), and publication bias was determined using the Begg's test and Egger's test ( $p<0.05$ was considered statistically significant for publication bias). We used MetaEssentials tools for the meta-analysis process. The criterion of publication bias assessment approach using the GRADE System, consisted of selection, performance, attrition, detection, and reporting bias. The variables used for subgroup analysis were the method of study (in vivo or in vitro), type of reference food, and type of crops. 
Table 1. GRADE evidence profile for chemical properties and starchy food sources related to GI.

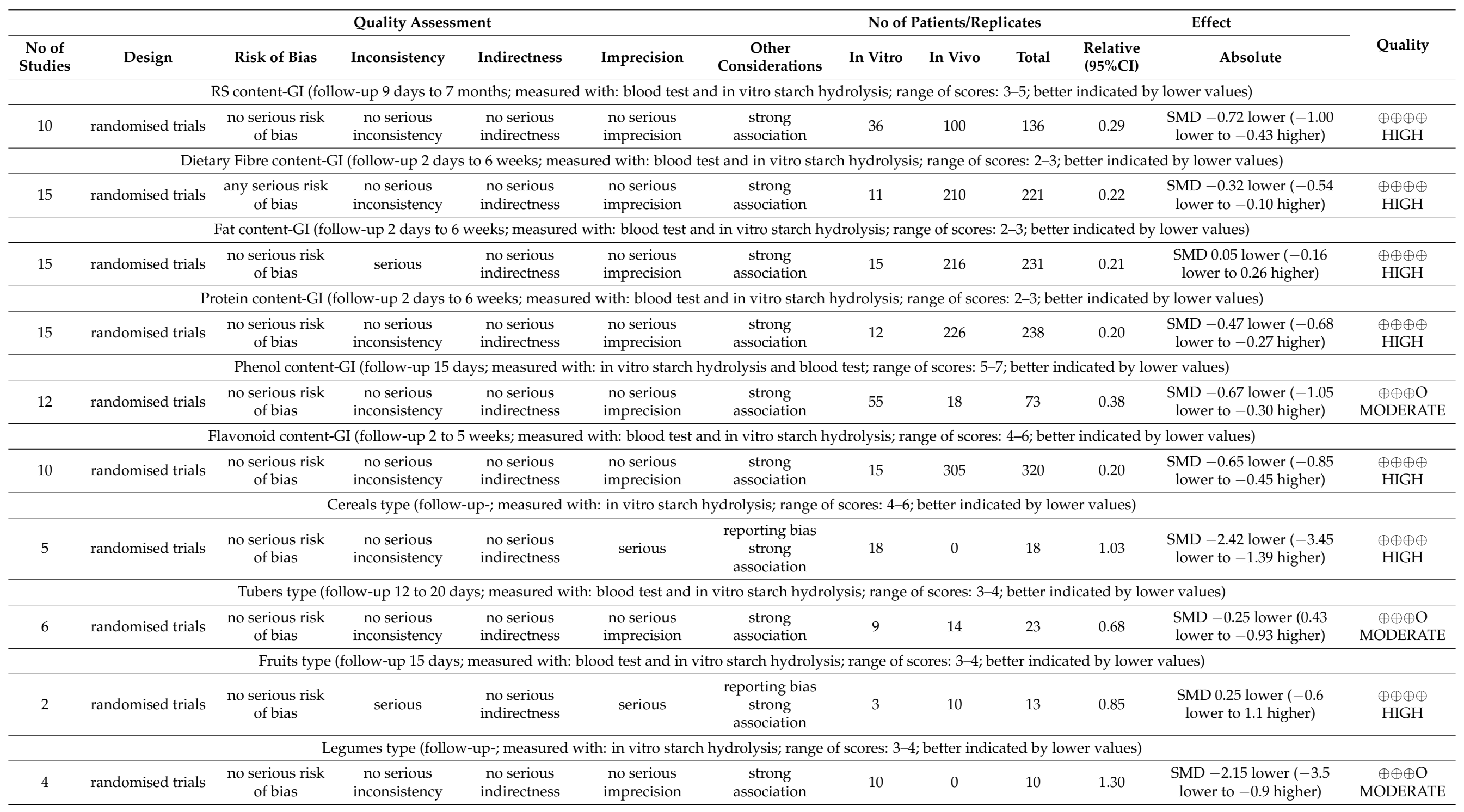




\section{Results}

\subsection{Trial Selection and Risk of Bias Assessment}

A total of sixty articles (from 338 articles) were selected for full-text review, resulting in fifty-seven articles [17-61] that met the inclusion criteria. Eight of them were rejected due to a lack of essential data. Five additional articles $[25,26,47,50,51]$ from reference lists of identified trials were included in the study because they met the inclusion criteria. In total, the meta-analysis involved fifty-seven articles, as exhibited in Figure 1. According to the Cochrane Collaboration tool, eleven trials $[6,24,29,32,33,37,38,42,48,51,54]$ were categorized as being at a low risk of bias, while forty-four were categorized as unclear $[17,19-23,25,27,28,30,31,34-36,39-41,43-47,49,50,52,53,55-62]$, and two were categorized as being at a high risk of bias $[18,26]$. Details about the risk of bias are supplied in Figures 2 and 3.

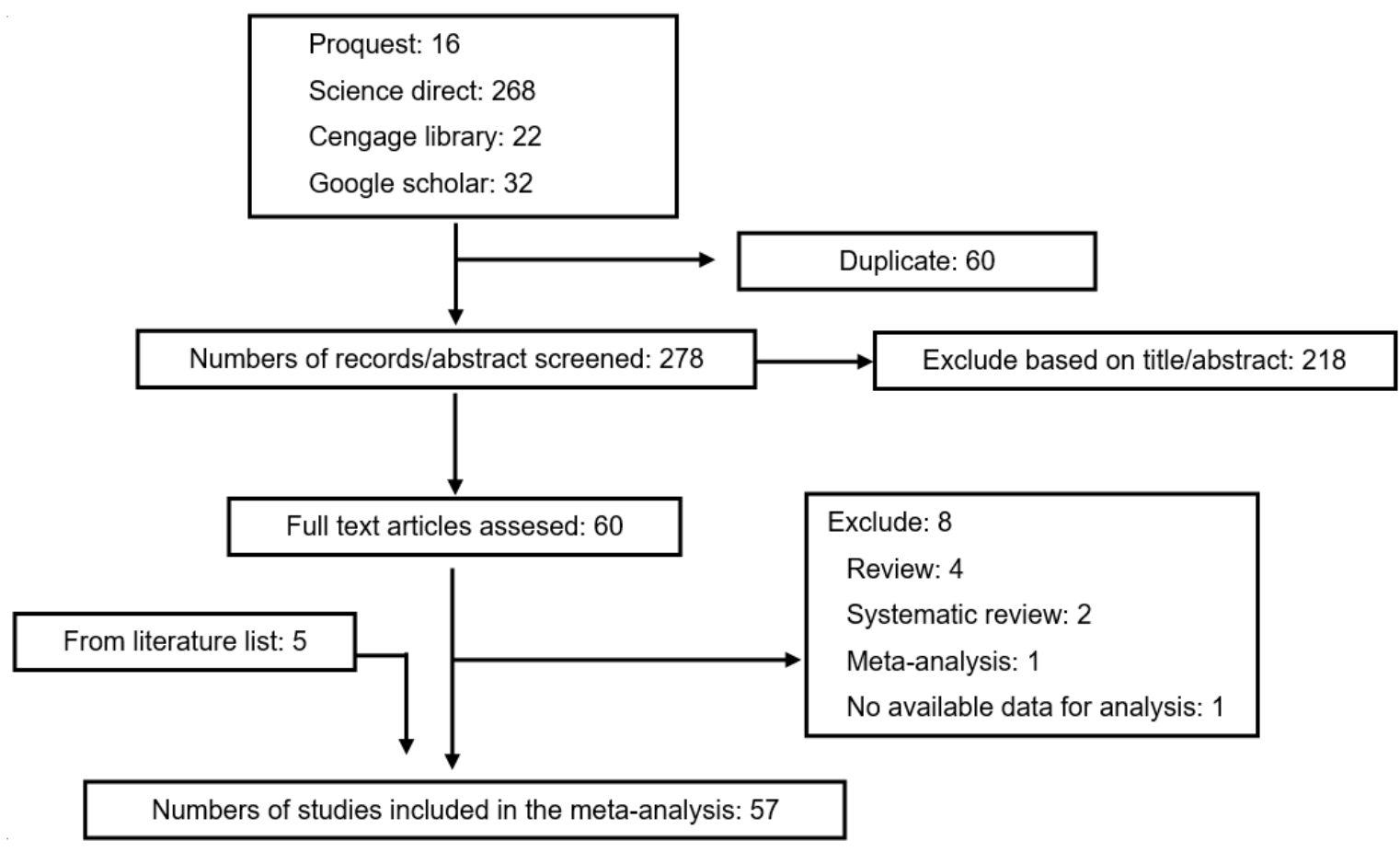

Figure 1. The preferred reporting items for systematic reviews and meta-analyses (PRISMA) flow chart of the literature review process.

\subsection{Characteristics of Articles}

Fifty-seven studies, involving 936 participants, were published from 2002 to 2019. Twenty-six studies $[9-12,17,18,20,21,26,31,35,39,43-47,49,54-57,59-62]$ used an in vitro experiment, while thirty-two studies involved in vivo experiments. Only one study used both in vitro and in vivo data experiments [11]. The in vivo studies involved healthy participants, and some studies used rats [51,58]. The PICOS of this research is defined as Participants, Interventions, Comparisons, Outcomes, and Study Design. Participants in the in vivo experiment were healthy adults. Interventions were lower food chemical properties. Comparisons were higher food chemical properties. Outcomes of this research were resistant starch, dietary fibre, protein, phenolic, and flavonoid content significantly affecting GI starchy foods, while selected low-GI foods were sorghum and red kidney bean. The study design used in this research was the completely randomized design. Among fifty-seven included studies, forty-eight were selected for discussion of the relationship between chemical properties and GI value [17-54]. The remaining studies were used for the selection of low-GI carbohydrate-based foods [55-62]. All studies reported changes in glycemic index, four studies $[7,17-19]$ reported changes in amylose content 
to GI, ten studies [9-13,20-24] reported changes in resistant starch (RS) content to GI, fifteen studies reported a change in dietary fibre content to GI, fifteen studies reported a change in fat content to GI, fifteen studies reported a change in protein content to GI, twelve studies reported a change in phenol content to GI, ten studies reported a change in flavonoid content to GI, five studies reported a change in cereal type to GI, six studies reported a change in tuber type to GI, two studies reported a change in fruit type to GI, and four studies reported a change in legume type to GI. Detailed characteristics of eligible studies are presented in Tables 2 and 3.

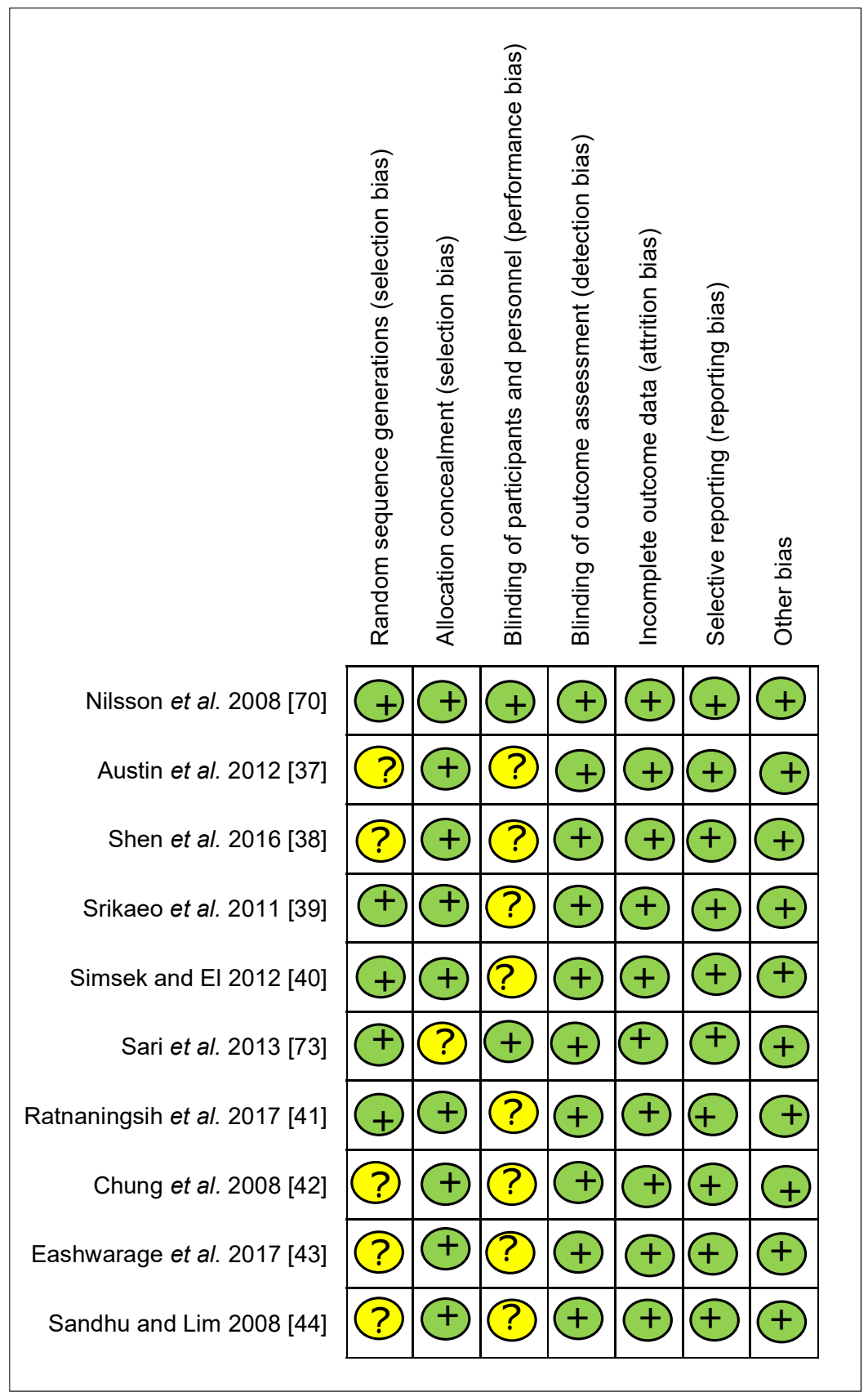

Figure 2. Cont. 


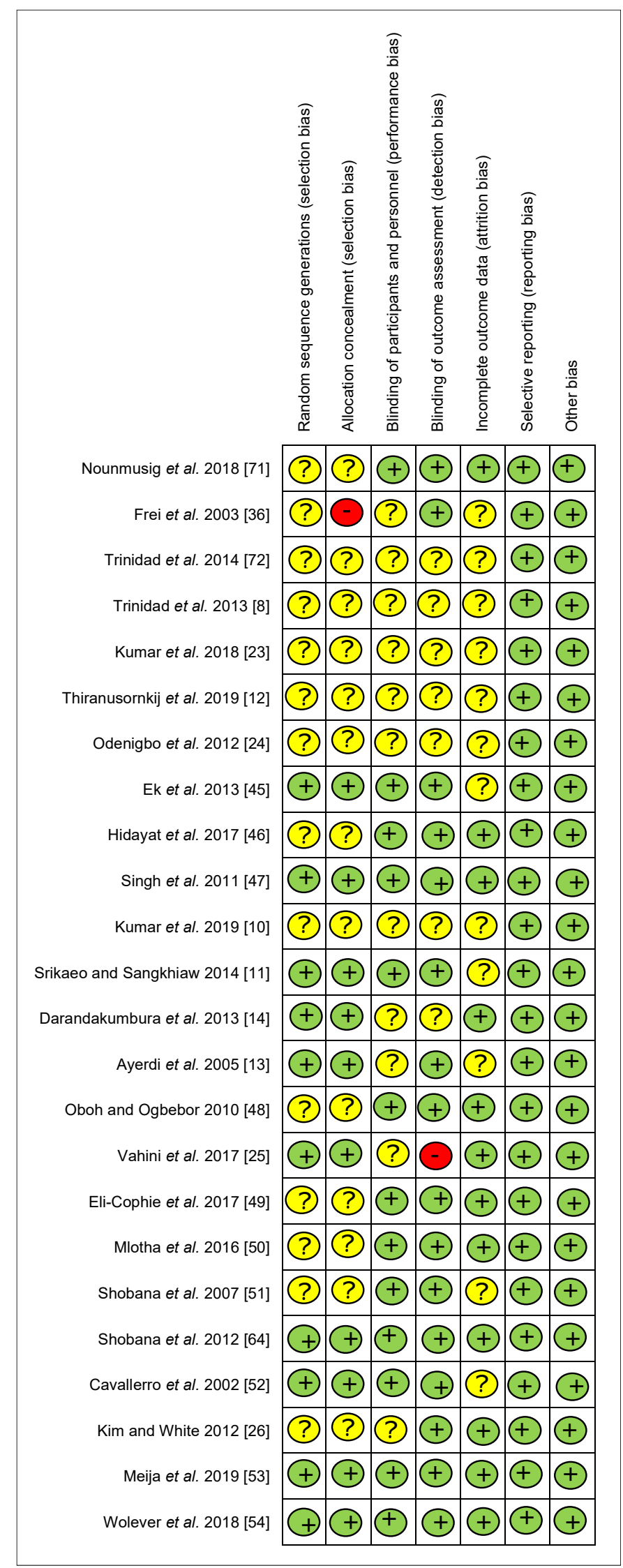

Figure 2. Cont. 


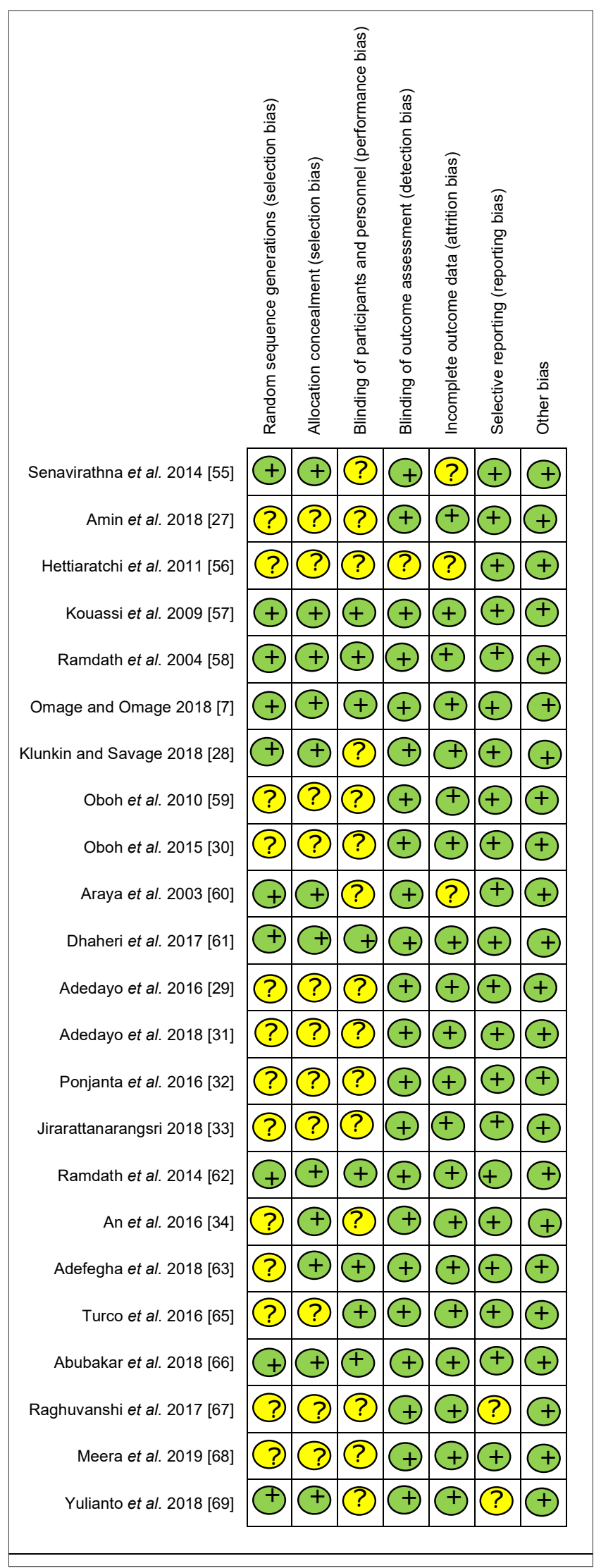

Figure 2. The result of the risk of bias assessment: each risk of bias item for the included studies (green means low risk of bias, yellow means unclear risk of bias, red means high risk of bias). 


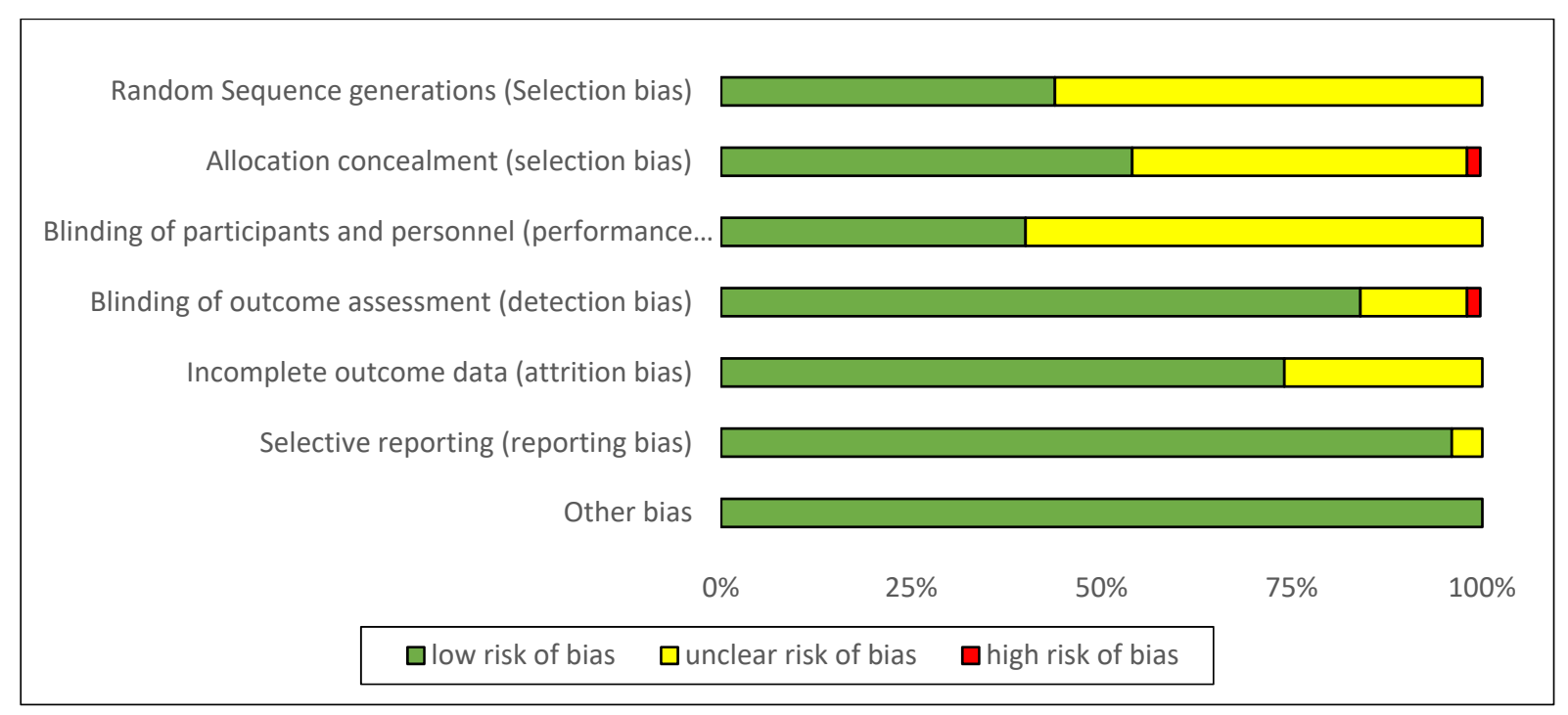

Figure 3. The result of the risk of bias assessment: each risk of bias item is shown as percentages across all included studies.

\subsection{Primary Outcome}

The primary outcome was the chemical properties determinant responsible for the GI of starchy foods and selected low-GI carbohydrate-based foods in the forest plots and funnel plots graphic (Figures 4, 5a, 6, and 7a). All studies (a total of 936 participants) provided data on the determinant of chemical properties (912 participants) and selected low-GI carbohydrate-based foods (twenty-four participants). Compared to other chemical properties, resistant starch and phenolic content significantly reduced the GI value of starchy foods (respectively, SMD: $-2.52,95 \%$ CI: -3.29 to $-1.75, p<0.001$; SMD: -0.72 , $95 \%$ CI: -1.26 to $-0.17, p=0.005$ ) with heterogeneity (respectively, $\mathrm{I}^{2}=84.23 \%, p<0.001$; $\mathrm{I}^{2}=73.64 \%, p=0.005$ ) (Tables 2,4 and 5). The lowest GI crop type is legumes (SMD: -2.15 , $95 \%$ CI: -3.45 to $-0.85, p<0.001)$ with heterogeneity $\left(\mathrm{I}^{2}=72.97 \%, p<0.001\right)$ (Figure 7 ). The heterogeneity among these studies may result from discrepancies in the population and control group.

\subsection{Subgroup Analysis}

Crop species, i.e., sorghum and red kidney bean, had low GI (respectively, SMD: $-0.69,95 \%$ CI: -2.33 to $0.96, p<0.001$; SMD: $-0.39,95 \% \mathrm{CI}:-2.37$ to $1.59, p=0.001$ ), with heterogeneity (respectively, $\mathrm{I}^{2}=81.4 \%, p<0.001 ; \mathrm{I}^{2}=73.0 \%, p=0.001$ ). All results of subgroup analyses are presented in Table 5 and Figure 7.

\subsection{Secondary Outcomes}

The contribution of six chemical properties to GI and five source types of carbohydrates to GI can be seen in Tables 4 and 5. Forty-eight studies [17-54] reported on the relationship between chemical properties and GI, while nine studies reported on the source types of carbohydrates to GI, respectively. Compared to other chemical properties of starchy foods or the source of carbohydrate-based foods, fat content did not reduce GI (SMD: $0.05,95 \% \mathrm{CI}$ : -0.16 to $0.27, p=0.312 ; \mathrm{I}^{2}=93.64 \%$ ), as was also found in tuber type (SMD: $-0.25,95 \% \mathrm{CI}:-0.93$ to $0.43, p=0.233 ; \mathrm{I}^{2}=79.4 \%$ ) or fruit type (SMD: $0.25,95 \% \mathrm{CI}$ : -0.60 to $1.10, p=0.284 ; \mathrm{I}^{2}=89.3 \%$ ). 
Table 2. Characteristics of in vitro studies included in the systematic review and meta-analysis. RS: resistant starch; GI: glycemic index; M: mean; SD: standard deviation.

\begin{tabular}{|c|c|c|c|c|c|c|c|c|c|}
\hline Author/Year & Country & Population & $\begin{array}{l}\text { No. of Patient/ } \\
\text { Replicates }\end{array}$ & Intervention & Control & Sample/Type & Method/Reference Food & $\begin{array}{l}\text { GI Value }(\mathrm{M} \pm \mathrm{SD}) \\
\text { Intervention/Control }\end{array}$ & $\begin{array}{c}\text { Follow } \\
\text { Up }\end{array}$ \\
\hline \multicolumn{10}{|c|}{ 1. RS Content-GI } \\
\hline Kumar et al./2018 [23] & India & - & 3 & Lower RS & Higher RS & Flour rice & In vitro $/ 0.2 \mathrm{~g}$ maltose & $71.48 \pm 0.21$ to $69.62 \pm 0.45$ & - \\
\hline $\begin{array}{l}\text { Odenigbo et al./ } \\
2012[24]\end{array}$ & Canada & - & 3 & Lower RS & Higher RS & French fries potato & $\begin{array}{l}\text { In vitro } / 50 \mathrm{mg} \\
\text { white bread }\end{array}$ & $52.16 \pm 2.41$ to $53.87 \pm 0.89$ & - \\
\hline Kumar et al./2019 [10] & India & - & 3 & Lower RS & Higher RS & $\begin{array}{l}\text { Flour rice ( } 2 \text { data)-normal } \\
\text { light, low light }\end{array}$ & In vitro $/ 0.2 \mathrm{~g}$ glucose & $\begin{array}{l}61.63 \pm 1.28 \text { to } 72.14 \pm 0.86 \\
63.14 \pm 0.77 \text { to } 74.08 \pm 1.06\end{array}$ & - \\
\hline $\begin{array}{c}\text { Srikaeo and } \\
\text { Sangkhiaw / } 2014 \text { [11] }\end{array}$ & Thailand & - & 3 & Lower RS & Higher RS & Cooked rice noodles & $\begin{array}{l}\text { In vitro } / 100 \mathrm{mg} \\
\text { white bread }\end{array}$ & $66.98 \pm 2.68$ to $83.66 \pm 1.02$ & - \\
\hline Ayerdi et al./2005 [13] & Mexico & - & 6 & Lower RS & Higher RS & $\begin{array}{c}\text { Cooked bean-corn } \\
\text { (3 data)-black beans, tortilla, } \\
\text { tortilla-bean }\end{array}$ & In vitro $/ 1 \mathrm{~g}$ white bread & $\begin{array}{l}22.00 \pm 3.02 \text { to } 27.00 \pm 1.81 \\
62.00 \pm 3.15 \text { to } 75.00 \pm 1.52 \\
35.00 \pm 1.38 \text { to } 51.00 \pm 3.81\end{array}$ & - \\
\hline \multicolumn{10}{|c|}{ 2. Dietary Fibre Content-GI } \\
\hline Vahini et al./2017 [25] & India & - & 2 & $\begin{array}{l}\text { Lower dietary } \\
\text { fibre }\end{array}$ & $\begin{array}{l}\text { Higher dietary } \\
\text { fibre }\end{array}$ & Corn flour boiled & In vitro/bread & $56.19 \pm 1.10$ to $82.57 \pm 2.25$ & - \\
\hline Amin et al./2018 [27] & India & - & 3 & $\begin{array}{l}\text { Lower dietary } \\
\text { fibre }\end{array}$ & $\begin{array}{l}\text { Higher dietary } \\
\text { fibre }\end{array}$ & $\begin{array}{c}\text { Rice flour by } \\
\text { enzymatic hydrolisis }\end{array}$ & In vitro $/ 50 \mathrm{~g}$ white bread & $46.10 \pm 0.20$ to $88.00 \pm 0.20$ & - \\
\hline \multicolumn{10}{|c|}{ 3. Fat Content-GI } \\
\hline $\begin{array}{c}\text { Klunkin and } \\
\text { Savage/2018 [28] }\end{array}$ & New Zealand & - & 3 & Lower fat & Higher fat & Flour purple rice & In vitro $/ 0.5 \mathrm{~g}$ glucose & $48.56 \pm 0.03$ to $63.11 \pm 0.02$ & - \\
\hline $\begin{array}{l}\text { Kim and White/ } \\
2012[26]\end{array}$ & USA & - & 3 & Lower fat & Higher fat & Oat flour (2 data)-raw, heated & $\begin{array}{l}\text { In vitro/100 mg } \\
\text { white bread }\end{array}$ & $\begin{array}{l}66.70 \pm 1.60 \text { to } 64.20 \pm 0.40 \\
77.20 \pm 0.50 \text { to } 82.70 \pm 0.90\end{array}$ & - \\
\hline $\begin{array}{l}\text { Odenigbo et al./ } \\
2012[24]\end{array}$ & Canada & - & 3 & Lower fat & Higher fat & French fries sweet potato & $\begin{array}{l}\text { In vitro/50 mg } \\
\text { white bread }\end{array}$ & $56.18 \pm 0.61$ to $54.64 \pm 0.71$ & - \\
\hline Amin et al./2018 [27] & India & - & 3 & Lower fat & Higher fat & $\begin{array}{c}\text { Rice flour by } \\
\text { enzymatic hydrolisis }\end{array}$ & In vitro/50 g white bread & $46.10 \pm 0.20$ to $88.00 \pm 0.20$ & - \\
\hline \multicolumn{10}{|c|}{ 4. Protein Content-GI } \\
\hline $\begin{array}{l}\text { Kim and White/ } \\
2012[26]\end{array}$ & USA & - & 3 & Lower protein & Higher protein & Oat flour (2 data)-raw, heated & $\begin{array}{l}\text { In vitro } / 100 \mathrm{mg} \\
\text { white bread }\end{array}$ & $\begin{array}{l}64.20 \pm 0.40 \text { to } 61.10 \pm 0.90 \\
77.20 \pm 0.50 \text { to } 85.70 \pm 0.70\end{array}$ & - \\
\hline $\begin{array}{l}\text { Odenigbo et al./ } \\
2012[24]\end{array}$ & Canada & - & 3 & Lower protein & Higher protein & French fries sweet potato & $\begin{array}{l}\text { In vitro } / 50 \mathrm{mg} \\
\text { white bread }\end{array}$ & $52.16 \pm 2.41$ to $56.18 \pm 0.61$ & - \\
\hline
\end{tabular}


Table 2. Cont.

\begin{tabular}{|c|c|c|c|c|c|c|c|c|c|}
\hline Author/Year & Country & Population & $\begin{array}{l}\text { No. of Patient/ } \\
\text { Replicates }\end{array}$ & Intervention & Control & Sample/Type & Method/Reference Food & $\begin{array}{l}\text { GI Value }(\mathrm{M} \pm \mathrm{SD}) \\
\text { Intervention/Control }\end{array}$ & $\begin{array}{l}\text { Follow } \\
\text { Up }\end{array}$ \\
\hline Amin et al./2018 [27] & India & - & 3 & Lower protein & Higher protein & $\begin{array}{c}\text { Rice flour by } \\
\text { enzymatic hydrolisis }\end{array}$ & In vitro $/ 50 \mathrm{~g}$ white bread & $46.10 \pm 0.20$ to $88.00 \pm 0.20$ & - \\
\hline \multicolumn{10}{|c|}{ 5. Phenol Content-GI } \\
\hline $\begin{array}{l}\text { Adedayo et al./ } \\
\text { 2016 [29] }\end{array}$ & Nigeria & - & 3 & Lower phenol & Higher phenol & Banana fruit & In vitro/50 g glucose & $44.95 \pm 2.30$ to $45.49 \pm 2.17$ & - \\
\hline Oboh et al./2015 [30] & Nigeria & - & 3 & Lower phenol & Higher phenol & Banana-breadfruit fruit & In vitro/50 mg glucose & $52.78 \pm 0.81$ to $64.50 \pm 1.23$ & - \\
\hline $\begin{array}{l}\text { Adedayo et al./ } \\
2018 \text { [31] }\end{array}$ & Nigeria & - & 3 & Lower phenol & Higher phenol & $\begin{array}{l}\text { Foreign and Ofada Rice } \\
\text { (raw-cooked)-2 data }\end{array}$ & In vitro $/ 50 \mathrm{~g}$ glucose & $\begin{array}{l}49.00 \pm 4.03 \text { to } 48.40 \pm 3.67 \\
51.80 \pm 3.01 \text { to } 49.20 \pm 2.99\end{array}$ & - \\
\hline $\begin{array}{l}\text { Ponjanta et al./ } \\
2016[32]\end{array}$ & Thailand & - & 3 & Lower phenol & Higher phenol & $\begin{array}{l}\text { Raw rice (white to purple, } \\
\text { red, black rice)-3 data }\end{array}$ & In vitro/50 g white bread & $\begin{array}{l}68.50 \pm 0.28 \text { to } 83.59 \pm 5.38 \\
80.40 \pm 4.02 \text { to } 81.87 \pm 0.68 \\
82.79 \pm 2.23 \text { to } 78.92 \pm 4.12\end{array}$ & - \\
\hline $\begin{array}{c}\text { Jirarattanarangsri/ } \\
2018 \text { [33] }\end{array}$ & Thailand & - & 3 & Lower phenol & Higher phenol & $\begin{array}{c}\text { Cooked corn (purple waxy } \\
\text { corn with ears and without } \\
\text { ears)-2 data }\end{array}$ & In vitro $/ 50 \mathrm{~g}$ glucose & $\begin{array}{l}95.80 \pm 0.50 \text { to } 96.20 \pm 0.20 \\
97.20 \pm 0.80 \text { to } 96.10 \pm 0.40\end{array}$ & - \\
\hline $\begin{array}{c}\text { Klunkin and } \\
\text { Savage/2018 [28] }\end{array}$ & New Zealand & - & 3 & Lower phenol & Higher phenol & $\begin{array}{c}\text { Cooked cereal } \\
\text { (wheat-purple rice) }\end{array}$ & In vitro $/ 50 \mathrm{~g}$ white bread & $48.56 \pm 0.03$ to $63.11 \pm 0.02$ & - \\
\hline $\begin{array}{l}\text { Thiranusornkij } \\
\text { et al./2019 [12] }\end{array}$ & Thailand & - & 3 & Lower phenol & Higher phenol & $\begin{array}{c}\text { Rice flour (Hom } \\
\text { Mali-Riceberry flour) }\end{array}$ & In vitro $/ 50 \mathrm{~g}$ glucose & $65.40 \pm 4.50$ to $87.10 \pm 4.85$ & - \\
\hline $\begin{array}{l}\text { Adefegha et al./ } \\
2018 \text { [63] }\end{array}$ & Nigeria & - & 3 & Lower phenol & Higher phenol & Wheat (raw flour-paste flour) & In vitro/50 g glucose & $63.15 \pm 2.30$ to $71.92 \pm 2.17$ & - \\
\hline $\begin{array}{c}\text { Adedayo et al./2018 } \\
\text { [35] }\end{array}$ & Nigeria & - & 3 & Lower phenol & Higher phenol & $\begin{array}{c}\text { Yam (white } \\
\text { bitter-yellow bitter) }\end{array}$ & In vitro $/ 25 \mathrm{mg}$ glucose & $56.25 \pm 0.81$ to $58.95 \pm 0.81$ & - \\
\hline \multicolumn{10}{|c|}{ 6. Flavonoid Content-GI } \\
\hline $\begin{array}{c}\text { Adedayo et al./ } \\
2018[31]\end{array}$ & Nigeria & - & 3 & Lower flavonoid & $\begin{array}{l}\text { Higher } \\
\text { flavonoid }\end{array}$ & $\begin{array}{l}\text { Foreign and Ofada Rice } \\
\text { (raw-cooked)-2 data }\end{array}$ & In vitro $/ 50 \mathrm{~g}$ glucose & $\begin{array}{l}49.00 \pm 4.03 \text { to } 48.40 \pm 3.67 \\
51.80 \pm 3.01 \text { to } 49.20 \pm 2.99\end{array}$ & \\
\hline $\begin{array}{c}\text { Klunkin and } \\
\text { Savage/2018 [28] }\end{array}$ & New Zealand & - & 3 & Lower flavonoid & $\begin{array}{l}\text { Higher } \\
\text { flavonoid }\end{array}$ & $\begin{array}{c}\text { Cooked cereal } \\
\text { (wheat-purple rice) }\end{array}$ & In vitro/50 g white bread & $48.56 \pm 0.03$ to $63.11 \pm 0.02$ & - \\
\hline An et al./2016 [34] & Korea & - & 3 & Lower flavonoid & $\begin{array}{c}\text { Higher } \\
\text { flavonoid }\end{array}$ & $\begin{array}{l}\text { Rice flour (black rice-phenolic } \\
\text { enriched extract) }\end{array}$ & In vitro $/ 5 \mathrm{~g}$ white bread & $69.77 \pm 1.26$ to $79.23 \pm 1.63$ & - \\
\hline $\begin{array}{c}\text { Adefegha et al./ } \\
2018 \text { [63] }\end{array}$ & Nigeria & - & 3 & Lower flavonoid & $\begin{array}{l}\text { Higher } \\
\text { flavonoid }\end{array}$ & Wheat (raw flour-paste flour) & In vitro/50 g glucose & $63.15 \pm 2.30$ to $71.92 \pm 2.17$ & - \\
\hline
\end{tabular}


Table 2. Cont.

\begin{tabular}{|c|c|c|c|c|c|c|c|c|c|}
\hline Author/Year & Country & Population & $\begin{array}{l}\text { No. of Patient/ } \\
\text { Replicates }\end{array}$ & Intervention & Control & Sample/Type & Method/Reference Food & $\begin{array}{l}\text { GI Value (M } \pm \text { SD) } \\
\text { Intervention/Control }\end{array}$ & $\begin{array}{c}\text { Follow } \\
\text { Up }\end{array}$ \\
\hline \multicolumn{10}{|c|}{ 7. Amylose Content-GI } \\
\hline Frei et al./2003 [36] & Germany & - & 3 & $\begin{array}{c}\text { Low amylose } \\
\text { rice }\end{array}$ & $\begin{array}{l}\text { Medium-high } \\
\text { amylose rice }\end{array}$ & $\begin{array}{l}\text { Cooked Rice/Brown } \\
\text { Rice-milled }\end{array}$ & $\begin{array}{l}\text { In vitro/50 mg } \\
\text { white bread }\end{array}$ & $\begin{array}{l}96.90 \pm 4.33 \text { to } 68.00 \pm 6.41 \\
68.50 \pm 5.54 \text { to } 87.30 \pm 4.68\end{array}$ & - \\
\hline \multicolumn{10}{|c|}{ Lower-Higher Category RS [Selected low GI Carbohydrate] } \\
\hline \multicolumn{10}{|c|}{ 1. Cereals Category } \\
\hline $\begin{array}{l}\text { Thiranusornkij } \\
\text { et al./2019 [12] }\end{array}$ & Thailand & - & 3 & Lower RS & Higher RS & Rice & In vitro/50 g glucose & $65.40 \pm 4.50$ to $87.10 \pm 4.85$ & - \\
\hline Frei et al./2003 [36] & Germany & - & 3 & Lower RS & Higher RS & Waxy rice & $\begin{array}{l}\text { In vitro/50 mg } \\
\text { white bread }\end{array}$ & $92.30 \pm 8.31$ to $109.20 \pm 1.56$ & - \\
\hline Ayerdi et al./2005 [13] & Mexico & - & 6 & Lower RS & Higher RS & Corn & In vitro/1 g white bread & $62.00 \pm 3.15$ to $75.00 \pm 1.52$ & - \\
\hline Austin et al./2012 [37] & USA & - & 3 & Lower RS & Higher RS & Sorghum & $\begin{array}{c}\text { In vitro/50 mg } \\
\text { white bread }\end{array}$ & $88.00 \pm 5.00$ to $92.00 \pm 4.30$ & - \\
\hline Shen et al./2016 [38] & China & - & 3 & Lower RS & Higher RS & Barley & $\begin{array}{l}\text { In vitro } / 50 \mathrm{mg} \\
\text { white bread }\end{array}$ & $51.65 \pm 0.02$ to $59.67 \pm 0.02$ & - \\
\hline \multicolumn{10}{|c|}{ 2. Tubers Category } \\
\hline Srikaeo et al./2011 [39] & Thailand & - & 2 & Lower RS & Higher RS & Canna & $\begin{array}{c}\text { In vitro } / 0.5 \mathrm{~g} \text { rice noodle } \\
100 \% \text { amylose }\end{array}$ & $88.00 \pm 1.80$ to $97.00 \pm 2.20$ & - \\
\hline $\begin{array}{l}\text { Odenigbo et al./ } \\
2012[24]\end{array}$ & Canada & - & 3 & Lower RS & Higher RS & Sweet potato & $\begin{array}{c}\text { In vitro } / 50 \mathrm{mg} \\
\text { white bread }\end{array}$ & $52.16 \pm 2.41$ to $53.87 \pm 0.89$ & - \\
\hline $\begin{array}{c}\text { Simsek and El/ } \\
2012 \text { [40] }\end{array}$ & Turkey & - & 2 & Lower RS & Higher RS & Taro & $\begin{array}{c}\text { In vitro } / 50 \mathrm{mg} \\
\text { white bread }\end{array}$ & $74.10 \pm 1.30$ to $86.60 \pm 0.80$ & - \\
\hline Srikaeo et al./2011 [39] & Thailand & - & 2 & Lower RS & Higher RS & Cassava & $\begin{array}{c}\text { In vitro } / 0.5 \mathrm{~g} \text { rice noodle } \\
100 \% \text { amylose }\end{array}$ & $\begin{array}{c}109.00 \pm 1.20 \text { to } 105.00 \pm \\
2.40\end{array}$ & - \\
\hline \multicolumn{10}{|c|}{ 3. Fruits Category } \\
\hline Oboh et al./2015 [30] & Nigeria & - & 3 & Lower RS & Higher RS & Papaya-breadfruit & In vitro/50 mg glucose & $64.50 \pm 1.23$ to $55.29 \pm 1.33$ & - \\
\hline \multicolumn{10}{|c|}{ 4. Legumes Category } \\
\hline $\begin{array}{l}\text { Ratnaningsih } \\
\text { et al./2017 [41] }\end{array}$ & Indonesia & - & 2 & Lower RS & Higher RS & Cowpea & $\begin{array}{l}\text { In vitro/100 mg } \\
\text { white bread }\end{array}$ & $45.46 \pm 0.23$ to $47.74 \pm 0.19$ & - \\
\hline Chung et al./ 2008 [42] & Canada & - & 2 & Lower RS & Higher RS & Red kidney bean & $\begin{array}{l}\text { In vitro } / 50 \mathrm{mg} \\
\text { white bread }\end{array}$ & $12.00 \pm 0.10$ to $12.20 \pm 0.40$ & - \\
\hline $\begin{array}{c}\text { Eashwarage et al./ } \\
2017 \text { [43] }\end{array}$ & Sri Lanka & - & 3 & Lower RS & Higher RS & Mung bean & In vitro $/ 1 \mathrm{~g}$ white bread & $41.54 \pm 0.25$ to $42.05 \pm 0.09$ & - \\
\hline $\begin{array}{l}\text { Sandhu and Lim/ } \\
2008 \text { [44] }\end{array}$ & South Korea & - & 3 & Lower RS & Higher RS & Pea & In vitro/50 g white bread & $44.20 \pm 0.60$ to $48.90 \pm 0.40$ & - \\
\hline
\end{tabular}


Table 3. Characteristics of in vivo studies included in the systematic review and meta-analysis. RS: resistant starch; GI: glycemic index; M: mean; SD: standard deviation.

\begin{tabular}{|c|c|c|c|c|c|c|c|c|c|}
\hline Author/Year & Country & Population & $\begin{array}{c}\text { No. of Pa- } \\
\text { tient/Replicates }\end{array}$ & Intervention & Control & Sample/Type & $\begin{array}{l}\text { Method/Reference } \\
\text { Food }\end{array}$ & $\begin{array}{l}\text { GI Value }(\mathbf{M} \pm \mathrm{SD}) \\
\text { Intervention/Control }\end{array}$ & Follow Up \\
\hline \multicolumn{10}{|c|}{ 1. RS Content-GI } \\
\hline $\begin{array}{l}\text { Ek et al./ } \\
2013[45]\end{array}$ & Australia & $\begin{array}{l}\text { Adults } \\
\text { (healthy) }\end{array}$ & $\begin{array}{c}10,27 / 10 \\
\text { (12 males, } \\
17 \text { females })\end{array}$ & Lower RS & Higher RS & Boiled potato $\left(4^{\prime}\right)$ & $\begin{array}{c}\text { In vivo/ } \\
50 \mathrm{mg} \text { glucose }\end{array}$ & $82.00 \pm 9.49$ to $93.00 \pm 31.62$ & 12-20 days \\
\hline $\begin{array}{l}\text { Hidayat et al./ } \\
2017 \text { [46] }\end{array}$ & Indonesia & $\begin{array}{l}\text { Adults } \\
\text { (healthy) }\end{array}$ & $10,10 / 10$ & Lower RS & Higher RS & Corn based-rice analogues & $\begin{array}{c}\text { In vivo/ } \\
50 \text { g glucose }\end{array}$ & $34.79 \pm 2.11$ to $40.77 \pm 2.12$ & 12 days \\
\hline $\begin{array}{l}\text { Singh et al./ } \\
2011[47]\end{array}$ & Jamaica & $\begin{array}{l}\text { Adults } \\
\text { (healthy) }\end{array}$ & $\begin{array}{l}10 / 10-5 \text { males, } \\
5 \text { females }\end{array}$ & Lower RS & Higher RS & $\begin{array}{l}\text { Cooked sweet potato ( } 4 \text { data)- } \\
\text { boiled, fried, baked, roasted }\end{array}$ & $\begin{array}{l}\text { In vivo/ } \\
50 \text { g glucose }\end{array}$ & $\begin{array}{c}49.00 \pm 12.65 \text { to } 46.00 \pm 12.65 \\
68.00 \pm 9.49 \text { to } 75.00 \pm 9.49 \\
91.00 \pm 9.49 \text { to } 87.00 \pm 12.65 \\
89.00 \pm 9.49 \text { to } 90.00 \pm 9.49\end{array}$ & 7 months \\
\hline $\begin{array}{l}\text { Srikaeo and } \\
\text { Sangkhiaw/ } \\
2014[11]\end{array}$ & Thailand & $\begin{array}{l}\text { Adults } \\
\text { (healthy) }\end{array}$ & $\begin{array}{l}10 / 10-5 \text { males, } \\
5 \text { females }\end{array}$ & Lower RS & Higher RS & Cooked rice noodles & In vivo $/ 50 \mathrm{~g}$ bread & $51.84 \pm 1.95$ to $63.62 \pm 4.69$ & 9 days \\
\hline $\begin{array}{l}\text { Darandakumbura } \\
\text { et al./2013 [14] }\end{array}$ & Srilanka & $\begin{array}{l}\text { Adults } \\
\text { (healthy) }\end{array}$ & $\begin{array}{l}10 / 10-5 \text { males, } \\
5 \text { females }\end{array}$ & Lower RS & Higher RS & $\begin{array}{l}\text { Cooked rice ( } 3 \text { data)-cultivar, } \\
\text { cooking method, parboiled }\end{array}$ & $\begin{array}{l}\text { In vivo/ } \\
50 \text { g glucose }\end{array}$ & $\begin{array}{l}68.00 \pm 2.00 \text { to } 70.00 \pm 1.00 \\
71.00 \pm 2.00 \text { to } 72.00 \pm 2.00 \\
71.00 \pm 1.00 \text { to } 68.00 \pm 1.00\end{array}$ & $\begin{array}{l}1.5 \text { months } \\
\text { (42 days) }\end{array}$ \\
\hline \multicolumn{10}{|c|}{ 2. Dietary Fibre Content-GI } \\
\hline $\begin{array}{c}\text { Eli-Cophie } \\
\text { et al./2017 [49] }\end{array}$ & Ghana & $\begin{array}{l}\text { Adults } \\
\text { (healthy) }\end{array}$ & $\begin{array}{l}\text { 10/10-8 males, } \\
2 \text { females }\end{array}$ & $\begin{array}{l}\text { Lower dietary } \\
\text { fibre }\end{array}$ & $\begin{array}{l}\text { Higher dietary } \\
\text { fibre }\end{array}$ & $\begin{array}{l}\text { Cassava Corn-Fermented Corn } \\
\text { (local food in Ghana) }\end{array}$ & $\begin{array}{c}\text { In vivo/ } \\
50 \text { g glucose }\end{array}$ & $41.00 \pm 21.50$ to $73.00 \pm 15.81$ & 21 days \\
\hline $\begin{array}{c}\text { Mlotha } \\
\text { et al./2016 [50] }\end{array}$ & Malawi & $\begin{array}{l}\text { Adults } \\
\text { (healthy) }\end{array}$ & $\begin{array}{l}\text { 11/11-6 males, } \\
5 \text { females }\end{array}$ & $\begin{array}{l}\text { Lower dietary } \\
\text { fibre }\end{array}$ & $\begin{array}{l}\text { Higher dietary } \\
\text { fibre }\end{array}$ & $\begin{array}{l}\text { Cooked dehulled-whole maize } \\
\text { (porridges) }\end{array}$ & $\begin{array}{c}\text { In vivo/ } \\
50 \text { g glucose }\end{array}$ & $106.72 \pm 47.83$ to $74.90 \pm 46.22$ & 21 days \\
\hline $\begin{array}{c}\text { Shobana } \\
\text { et al./2007 [51] }\end{array}$ & India & $\begin{array}{l}\text { Adults } \\
\text { (healthy) }\end{array}$ & $\begin{array}{l}8 / 8-5 \text { males, } \\
3 \text { females }\end{array}$ & $\begin{array}{l}\text { Lower dietary } \\
\text { fibre }\end{array}$ & $\begin{array}{l}\text { Higher dietary } \\
\text { fibre }\end{array}$ & $\begin{array}{l}\text { Cooked expanded rice-wheat } \\
\text { (food formulation) }\end{array}$ & $\begin{array}{c}\text { In vivo/ } \\
50 \mathrm{~g} \text { white bread }\end{array}$ & $55.40 \pm 9.00$ to $105.00 \pm 6.00$ & 25 days \\
\hline $\begin{array}{l}\text { Cavallerro } \\
\text { et al./2002 [52] }\end{array}$ & Italy & $\begin{array}{l}\text { Adults } \\
\text { (healthy) }\end{array}$ & $\begin{array}{l}8 / 8-3 \text { males } \\
5 \text { females }\end{array}$ & $\begin{array}{l}\text { Lower dietary } \\
\text { fibre }\end{array}$ & $\begin{array}{l}\text { Higher dietary } \\
\text { fibre }\end{array}$ & $\begin{array}{c}100 \% \text { Bread Wheat-20\% Water } \\
\text { Extracted Fraction Barley }\end{array}$ & $\begin{array}{c}\text { In vivo/ } \\
50 \text { g glucose }\end{array}$ & $69.67 \pm 20.34$ to $89.49 \pm 35.10$ & 15 days \\
\hline $\begin{array}{l}\text { Meija et al./2019 } \\
\text { [53] }\end{array}$ & $\begin{array}{c}\text { Latvia- } \\
\text { Norway }\end{array}$ & $\begin{array}{c}\text { Adults } \\
\text { (healthy) }\end{array}$ & $\begin{array}{c}21 / 18 \\
9-5 \text { male, } 4 \text { female }\end{array}$ & $\begin{array}{l}\text { Lower dietary } \\
\text { fibre }\end{array}$ & $\begin{array}{l}\text { Higher dietary } \\
\text { fibre }\end{array}$ & Cooked wheat-triticale & $\begin{array}{c}\text { In vivo/ } \\
50 \text { g glucose }\end{array}$ & $53.85 \pm 4.86$ to $75.76 \pm 3.26$ & 5 days \\
\hline $\begin{array}{c}\text { Wolever } \\
\text { et al./2018 [54] }\end{array}$ & Canada & $\begin{array}{c}\text { Adults } \\
\text { (healthy) }\end{array}$ & $\begin{array}{l}51 / 40-24 \text { male } \\
16 \text { female }\end{array}$ & $\begin{array}{l}\text { Lower dietary } \\
\text { fibre }\end{array}$ & $\begin{array}{l}\text { Higher dietary } \\
\text { fibre }\end{array}$ & Cooked rice cereal-oat & $\begin{array}{c}\text { In vivo/ } \\
50 \mathrm{~g} \text { rice cereal }\end{array}$ & $53.85 \pm 4.86$ to $75.76 \pm 3.26$ & $2-6$ weeks \\
\hline $\begin{array}{l}\text { Senavirathna } \\
\text { et al./2014 [55] }\end{array}$ & Sri Lanka & $\begin{array}{c}\text { Adults } \\
\text { (healthy) }\end{array}$ & $10 / 10$ & $\begin{array}{l}\text { Lower dietary } \\
\text { fibre } \\
\end{array}$ & $\begin{array}{l}\text { Higher dietary } \\
\text { fibre }\end{array}$ & Cooked underutilized tuber & $\begin{array}{c}\text { In vivo/ } \\
50 \mathrm{~g} \text { white bread }\end{array}$ & $82.00 \pm 25.30$ to $64.00 \pm 28.46$ & $\approx 15$ days \\
\hline
\end{tabular}


Table 3. Cont.

\begin{tabular}{|c|c|c|c|c|c|c|c|c|c|}
\hline Author/Year & Country & Population & $\begin{array}{l}\text { No. of Pa- } \\
\text { tient/Replicates }\end{array}$ & Intervention & Control & Sample/Type & $\begin{array}{l}\text { Method/Reference } \\
\text { Food }\end{array}$ & $\begin{array}{l}\text { GI Value }(\mathrm{M} \pm \mathrm{SD}) \\
\text { Intervention/Control }\end{array}$ & Follow Up \\
\hline $\begin{array}{l}\text { Hettiaratchi } \\
\text { et al./2011 [56] }\end{array}$ & Sri Lanka & $\begin{array}{l}\text { Adults } \\
\text { (healthy) }\end{array}$ & 10 & $\begin{array}{l}\text { Lower dietary } \\
\text { fibre }\end{array}$ & $\begin{array}{l}\text { Higher dietary } \\
\text { fibre }\end{array}$ & Banana fruit & $\begin{array}{c}\text { In vivo/ } \\
50 \mathrm{~g} \text { white bread }\end{array}$ & $61.00 \pm 15.81$ to $67.00 \pm 22.14$ & $\approx 15$ days \\
\hline $\begin{array}{c}\text { Kouassi } \\
\text { et al./2009 [57] }\end{array}$ & Cote d'Ivoire & $\begin{array}{l}\text { Adults } \\
\text { (healthy) }\end{array}$ & 10-10 males & $\begin{array}{l}\text { Lower dietary } \\
\text { fibre }\end{array}$ & $\begin{array}{l}\text { Higher dietary } \\
\text { fibre }\end{array}$ & Cooked yam ( 2 data)-oven, boiled & $\begin{array}{c}\text { In vivo/ } \\
50 \text { g glucose }\end{array}$ & $\begin{array}{l}66.00 \pm 34.64 \text { to } 53.00 \pm 22.52 \\
54.00 \pm 32.91 \text { to } 60.00 \pm 31.18\end{array}$ & $\approx 27$ days \\
\hline $\begin{array}{l}\text { Ramdath } \\
\text { et al./2004 [58] }\end{array}$ & Carribean & $\begin{array}{l}\text { Adults } \\
\text { (healthy) }\end{array}$ & $\begin{array}{l}\text { 8-10-4 males, } \\
\text { 4-6 females }\end{array}$ & $\begin{array}{l}\text { Lower dietary } \\
\text { fibre }\end{array}$ & $\begin{array}{l}\text { Higher dietary } \\
\text { fibre }\end{array}$ & $\begin{array}{l}\text { Cooked staple in Carribean } \\
\text { (Tannia-green banana) }\end{array}$ & $\begin{array}{c}\text { In vivo/ } \\
50 \text { g white bread }\end{array}$ & $61.00 \pm 15.81$ to $67.00 \pm 22.14$ & $\approx 1$ months \\
\hline $\begin{array}{c}\text { Omage and } \\
\text { Omage/2018 [7] }\end{array}$ & Nigeria & $\begin{array}{c}\text { Adults } \\
\text { (healthy) }\end{array}$ & $\begin{array}{l}240 / 80-40 \text { males, } \\
40 \text { females }\end{array}$ & $\begin{array}{l}\text { Lower dietary } \\
\text { fibre }\end{array}$ & $\begin{array}{l}\text { Higher dietary } \\
\text { fibre }\end{array}$ & $\begin{array}{l}\text { Cooked mixed rice } \\
\text { bean-rice plantain }\end{array}$ & $\begin{array}{c}\text { In vivo/ } \\
50 \text { g glucose }\end{array}$ & $89.74 \pm 9.84$ to $86.60 \pm 49.82$ & 2 days \\
\hline \multicolumn{10}{|c|}{ 3. Fat Content-GI } \\
\hline $\begin{array}{l}\text { Oboh and } \\
\text { Ogbebor/ } \\
2010[48]\end{array}$ & Nigeria & $\begin{array}{l}\text { Adults } \\
\text { (healthy) }\end{array}$ & $\begin{array}{l}10-5 \text { males, } \\
5 \text { females }\end{array}$ & Lower fat & Higher fat & Cooked maize & $\begin{array}{l}\text { In vivo/ } \\
50 \text { g glucose }\end{array}$ & $38.89 \pm 3.13$ to $21.32 \pm 4.40$ & $\approx 9$ days \\
\hline $\begin{array}{c}\text { Mlotha } \\
\text { et al./2016 [50] }\end{array}$ & Malawi & $\begin{array}{l}\text { Adults } \\
\text { (healthy) }\end{array}$ & $\begin{array}{l}\text { 11-6 males, } \\
5 \text { females }\end{array}$ & Lower fat & Higher fat & Cooked maize & $\begin{array}{c}\text { In vivo/ } \\
50 \text { g glucose }\end{array}$ & $106.72 \pm 47.83$ to $74.90 \pm 46.22$ & 21 days \\
\hline $\begin{array}{c}\text { Shobana } \\
\text { et al./2007 [51] }\end{array}$ & India & $\begin{array}{l}\text { Adults } \\
\text { (healthy) }\end{array}$ & $\begin{array}{l}8-5 \text { males, } \\
3 \text { females }\end{array}$ & Lower fat & Higher fat & Cooked rice (popped rice) & $\begin{array}{c}\text { In vivo/ } \\
50 \text { g white bread }\end{array}$ & $109.00 \pm 8.00$ to $55.40 \pm 9.00$ & 25 days \\
\hline $\begin{array}{l}\text { Cavallerro } \\
\text { et al./2002 [52] }\end{array}$ & Italy & $\begin{array}{l}\text { Adults } \\
\text { (healthy) }\end{array}$ & $\begin{array}{l}8-3 \text { males, } \\
5 \text { females }\end{array}$ & Lower fat & Higher fat & $\begin{array}{c}\text { Bread ( } 20 \% \text { Water-Extracted } \\
\text { Fraction Barley-50\% Sieved } \\
\text { Fraction Barley) }\end{array}$ & $\begin{array}{l}\text { In vivo/ } \\
50 \text { g glucose }\end{array}$ & $74.46 \pm 43.78$ to $69.67 \pm 20.34$ & 15 days \\
\hline $\begin{array}{c}\text { Wolever } \\
\text { et al./2018 [54] }\end{array}$ & Canada & $\begin{array}{l}\text { Adults } \\
\text { (healthy) }\end{array}$ & $\begin{array}{l}40-24 \text { male, } \\
16 \text { female }\end{array}$ & Lower fat & Higher fat & Cooked rice cereal-oat & $\begin{array}{c}\text { In vivo/ } \\
50 \mathrm{~g} \text { rice cereal }\end{array}$ & $62.98 \pm 9.07$ to $100.00 \pm 0.00$ & $2-6$ weeks \\
\hline $\begin{array}{l}\text { Senavirathna } \\
\text { et al./2014 [55] }\end{array}$ & Sri Lanka & $\begin{array}{l}\text { Adults } \\
\text { (healthy) }\end{array}$ & 10 & Lower fat & Higher fat & Cooked underutilized tuber & $\begin{array}{c}\text { In vivo/ } \\
50 \text { g white bread }\end{array}$ & $110.00 \pm 25.30$ to $69.00 \pm 12.65$ & $\approx 15$ days \\
\hline $\begin{array}{c}\text { Shobana } \\
\text { et al./2012 [64] }\end{array}$ & India & $\begin{array}{l}\text { Adults } \\
\text { (healthy) }\end{array}$ & $\begin{array}{l}23 / 23-12 \text { males, } \\
11 \text { females }\end{array}$ & Lower fat & Higher fat & Cooked rice & $\begin{array}{c}\text { In vivo/ } \\
50 \text { g glucose }\end{array}$ & $77.00 \pm 19.18$ to $72.00 \pm 21.58$ & 8 days \\
\hline $\begin{array}{l}\text { Hettiaratchi } \\
\text { et al./2011 [56] }\end{array}$ & Sri Lanka & $\begin{array}{l}\text { Adults } \\
\text { (healthy) }\end{array}$ & 10 & Lower fat & Higher fat & Banana fruit & $\begin{array}{c}\text { In vivo/ } \\
50 \text { g white bread }\end{array}$ & $69.00 \pm 28.46$ to $61.00 \pm 18.97$ & $\approx 15$ days \\
\hline $\begin{array}{c}\text { Kouassi } \\
\text { et al./2009 [57] }\end{array}$ & Cote d'Ivoire & $\begin{array}{l}\text { Adults } \\
\text { (healthy) }\end{array}$ & 10-10 males & Lower fat & Higher fat & Cooked yam ( 2 data)-oven, boiled & $\begin{array}{c}\text { In vivo/ } \\
50 \text { g glucose }\end{array}$ & $\begin{array}{l}70.00 \pm 31.18 \text { to } 53.00 \pm 22.52 \\
67.00 \pm 27.71 \text { to } 51.00 \pm 22.52\end{array}$ & $\approx 27$ days \\
\hline $\begin{array}{l}\text { Ramdath } \\
\text { et al./2004 [58] }\end{array}$ & Carribean & $\begin{array}{l}\text { Adults } \\
\text { (healthy) }\end{array}$ & $8-10$ & Lower fat & Higher fat & $\begin{array}{l}\text { Cooked staple in Carribean } \\
\text { (white yam-dasheen) }\end{array}$ & $\begin{array}{c}\text { In vivo/ } \\
50 \text { g white bread }\end{array}$ & $88.00 \pm 28.46$ to $109.00 \pm 44.27$ & $\approx 1$ months \\
\hline $\begin{array}{c}\text { Omage and } \\
\text { Omage/2018 [7] }\end{array}$ & Nigeria & $\begin{array}{l}\text { Adults } \\
\text { (healthy) }\end{array}$ & $\begin{array}{l}80-40 \text { males, } \\
40 \text { females }\end{array}$ & Lower fat & Higher fat & $\begin{array}{l}\text { Cooked mixed rice } \\
\text { bean-rice plantain }\end{array}$ & $\begin{array}{l}\text { In vivo/ } \\
50 \text { g glucose }\end{array}$ & $86.93 \pm 56.71$ to $86.60 \pm 49.82$ & 2 days \\
\hline
\end{tabular}


Table 3. Cont.

\begin{tabular}{|c|c|c|c|c|c|c|c|c|c|}
\hline Author/Year & Country & Population & $\begin{array}{c}\text { No. of Pa- } \\
\text { tient/Replicates }\end{array}$ & Intervention & Control & Sample/Type & $\begin{array}{c}\text { Method/Reference } \\
\text { Food }\end{array}$ & $\begin{array}{l}\text { GI Value }(\mathrm{M} \pm \mathrm{SD}) \\
\text { Intervention/Control }\end{array}$ & Follow Up \\
\hline \multicolumn{10}{|c|}{ 4. Protein Content-GI } \\
\hline $\begin{array}{c}\text { Mlotha } \\
\text { et al./2016 [50] }\end{array}$ & Malawi & $\begin{array}{l}\text { Adults } \\
\text { (healthy) }\end{array}$ & $\begin{array}{l}\text { 11-6 males, } \\
5 \text { females }\end{array}$ & Lower protein & Higher protein & $\begin{array}{l}\text { Cooked dehulled-whole maize } \\
\text { (porridges) }\end{array}$ & $\begin{array}{c}\text { In vivo/ } \\
50 \text { g glucose }\end{array}$ & $106.72 \pm 47.83$ to $121.97 \pm 38.99$ & 21 days \\
\hline $\begin{array}{c}\text { Shobana } \\
\text { et al./2007 [51] }\end{array}$ & India & $\begin{array}{c}\text { Adults } \\
\text { (healthy) }\end{array}$ & $\begin{array}{l}8-5 \text { males, } \\
3 \text { females }\end{array}$ & Lower protein & Higher protein & $\begin{array}{l}\text { Cooked millet-wheat (food } \\
\text { formulation) }\end{array}$ & $\begin{array}{c}\text { In vivo/ } \\
50 \mathrm{~g} \text { white bread }\end{array}$ & $55.40 \pm 9.00$ to $93.40 \pm 7.00$ & 25 days \\
\hline $\begin{array}{c}\text { Cavallerro } \\
\text { et al./2002 [52] }\end{array}$ & Italy & $\begin{array}{l}\text { Adults } \\
\text { (healthy)) }\end{array}$ & $\begin{array}{l}8-3 \text { males, } \\
5 \text { females }\end{array}$ & Lower protein & Higher protein & $\begin{array}{c}\text { Bread (50\% Barley Flour-100\% } \\
\text { Bread Wheat) }\end{array}$ & $\begin{array}{c}\text { In vivo/ } \\
50 \text { g glucose }\end{array}$ & $89.49 \pm 35.10$ to $85.42 \pm 38.81$ & 15 days \\
\hline $\begin{array}{l}\text { Senavirathna } \\
\text { et al./2014 [55] }\end{array}$ & Sri Lanka & $\begin{array}{c}\text { Adults } \\
\text { (healthy) }\end{array}$ & 10 & Lower protein & Higher protein & Cooked underutilized tuber & $\begin{array}{c}\text { In vivo/ } \\
50 \mathrm{~g} \text { white bread }\end{array}$ & $64.00 \pm 28.46$ to $69.00 \pm 12.65$ & $\approx 15$ days \\
\hline $\begin{array}{c}\text { Shobana } \\
\text { et al./2012 [64] }\end{array}$ & India & $\begin{array}{l}\text { Adults } \\
\text { (healthy) }\end{array}$ & $\begin{array}{l}23-12 \text { males, } \\
11 \text { females }\end{array}$ & Lower protein & Higher protein & Cooked rice & $\begin{array}{c}\text { In vivo/ } \\
50 \text { g glucose }\end{array}$ & $70.20 \pm 17.26$ to $77.00 \pm 19.18$ & 8 days \\
\hline $\begin{array}{c}\text { Kouassi } \\
\text { et al./2009 [57] }\end{array}$ & Cote d'Ivoire & $\begin{array}{l}\text { Adults } \\
\text { (healthy) }\end{array}$ & 10-10 males & Lower protein & Higher protein & Cooked yam ( 2 data)-oven, boiled & $\begin{array}{c}\text { In vivo/ } \\
50 \text { g glucose }\end{array}$ & $\begin{array}{l}53.00 \pm 22.52 \text { to } 56.00 \pm 20.78 \\
60.00 \pm 31.18 \text { to } 54.00 \pm 32.91\end{array}$ & $\approx 27$ days \\
\hline $\begin{array}{l}\text { Ramdath } \\
\text { et al./2004 [58] }\end{array}$ & Carribean & $\begin{array}{l}\text { Adults } \\
\text { (healthy) }\end{array}$ & $8-10$ & Lower protein & Higher protein & $\begin{array}{l}\text { Cooked staple in Carribean } \\
\text { (tannia-green banana) }\end{array}$ & $\begin{array}{c}\text { In vivo/ } \\
50 \text { g white bread }\end{array}$ & $88.00 \pm 28.46$ to $109.00 \pm 44.27$ & $\approx 1$ months \\
\hline $\begin{array}{c}\text { Oboh } \\
\text { et al./2010 [59] }\end{array}$ & Nigeria & $\begin{array}{l}\text { Adults } \\
\text { (healthy) }\end{array}$ & 5 & Lower protein & Higher protein & $\begin{array}{l}\text { Cooked legumes (Cowpea black } \\
\text { white-Pigeonpea brown) }\end{array}$ & $\begin{array}{c}\text { In vivo/ } \\
50 \text { g glucose }\end{array}$ & $24.00 \pm 22.36$ to $30.00 \pm 24.60$ & $\approx 24$ days \\
\hline $\begin{array}{c}\text { Araya } \\
\text { et al./2003 [60] }\end{array}$ & Chile & $\begin{array}{l}\text { Adults } \\
\text { (healthy) }\end{array}$ & 10 males & Lower protein & Higher protein & Cooked legumes (bean-lentil) & $\begin{array}{c}\text { In vivo/ } \\
50 \mathrm{~g} \text { white bread }\end{array}$ & $49.30 \pm 29.50$ to $76.80 \pm 43.40$ & $\approx 3-6$ weeks \\
\hline $\begin{array}{c}\text { Dhaheri } \\
\text { et al./2017 [61] }\end{array}$ & $\begin{array}{l}\text { United Arab } \\
\text { Emirates }\end{array}$ & $\begin{array}{l}\text { Adults } \\
\text { (healthy) }\end{array}$ & $\begin{array}{l}37 / 15-6 \text { males, } \\
9 \text { females }\end{array}$ & Lower protein & Higher protein & Emirate cuisine (balalet-chami) & $\begin{array}{l}\text { In vivo/ } \\
50 \text { g glucose }\end{array}$ & $60.00 \pm 36.00$ to $63.00 \pm 19.36$ & $\approx 2$ months \\
\hline \multicolumn{10}{|c|}{ 5. Phenol Content-GI } \\
\hline $\begin{array}{l}\text { Ramdath } \\
\text { et al./2014 [62] }\end{array}$ & Canada & $\begin{array}{l}\text { Caucasian } \\
\text { Adults } \\
\text { (healthy) }\end{array}$ & $\begin{array}{l}9 / 9-3 \text { males, } \\
6 \text { females }\end{array}$ & Lower phenol & Higher phenol & $\begin{array}{l}\text { Pigmented potatoes (white-purple; } \\
\text { red-yellow)-2 data }\end{array}$ & $\begin{array}{l}\text { In vivo/ } \\
50 \text { g glucose }\end{array}$ & $\begin{array}{l}77.00 \pm 27.00 \text { to } 93.00 \pm 51.00 \\
78.00 \pm 42.00 \text { to } 81.00 \pm 48.00\end{array}$ & $\approx 15$ days \\
\hline $\begin{array}{c}\text { Turco } \\
\text { et al./2016 [65] }\end{array}$ & Italy & $\begin{array}{l}\text { Adults } \\
\text { (healthy) }\end{array}$ & $\begin{array}{l}13-2 \text { males, } \\
11 \text { females }\end{array}$ & Lower phenol & Higher phenol & Cooked pasta wheat-bean & $\begin{array}{l}\text { In vivo/ } \\
50 \text { g glucose }\end{array}$ & $40.00 \pm 16.22$ to $72.00 \pm 28.84$ & $\approx 15$ days \\
\hline
\end{tabular}


Table 3. Cont.

\begin{tabular}{|c|c|c|c|c|c|c|c|c|c|}
\hline Author/Year & Country & Population & $\begin{array}{c}\text { No. of Pa- } \\
\text { tient/Replicates }\end{array}$ & Intervention & Control & Sample/Type & $\begin{array}{l}\text { Method/Reference } \\
\text { Food }\end{array}$ & $\begin{array}{l}\text { GI Value }(\mathrm{M} \pm \mathrm{SD}) \\
\text { Intervention/Control }\end{array}$ & Follow Up \\
\hline \multicolumn{10}{|c|}{ 6. Flavonoid Content-GI } \\
\hline $\begin{array}{c}\text { Turco } \\
\text { et al./2016 [65] }\end{array}$ & Italy & $\begin{array}{l}\text { Adults } \\
\text { (healthy) }\end{array}$ & $\begin{array}{l}\text { 13/13- } 2 \text { males, } \\
11 \text { females }\end{array}$ & Lower flavonoid & $\begin{array}{l}\text { Higher } \\
\text { flavonoid }\end{array}$ & Cooked pasta wheat-bean & $\begin{array}{c}\text { In vivo/ } \\
50 \text { g glucose }\end{array}$ & $40.00 \pm 16.22$ to $72.00 \pm 28.84$ & $\approx 15$ days \\
\hline $\begin{array}{l}\text { Abubakar } \\
\text { et al./2018 [66] }\end{array}$ & Malaysia & $\begin{array}{c}\text { Rats } \\
\text { weighing } \\
160-200 \mathrm{~g}\end{array}$ & $\begin{array}{l}60 \text { males } \\
\text { Sprague-Dawley } \\
\text { rats }\end{array}$ & Lower flavonoid & $\begin{array}{l}\text { Higher } \\
\text { flavonoid }\end{array}$ & $\begin{array}{l}\text { Rice flour (germinated brown rice, } \\
\text { brown rice, white rice)-3 data }\end{array}$ & $\begin{array}{l}\text { In vivo/ } \\
500 \mathrm{mg} \text { glucose }\end{array}$ & $\begin{array}{l}67.60 \pm 2.27 \text { to } 64.30 \pm 3.51 \\
67.70 \pm 2.04 \text { to } 81.80 \pm 2.70 \\
65.60 \pm 3.51 \text { to } 84.70 \pm 2.81\end{array}$ & $\approx 5$ weeks \\
\hline $\begin{array}{l}\text { Raghuvanshi } \\
\text { et al./2017 [67] }\end{array}$ & India & $\begin{array}{l}\text { Adults } \\
\text { (healthy) }\end{array}$ & 10 & Lower flavonoid & $\begin{array}{l}\text { Higher } \\
\text { flavonoid }\end{array}$ & Cooked rice (red-white rice) & $\begin{array}{c}\text { In vivo/ } \\
50 \text { g glucose }\end{array}$ & $71.70 \pm 2.63$ to $63.15 \pm 0.91$ & $\approx 15$ days \\
\hline $\begin{array}{c}\text { Meera } \\
\text { et al./2019 [68] }\end{array}$ & India & $\begin{array}{l}\text { Adults } \\
\text { (healthy) }\end{array}$ & 12 & Lower flavonoid & $\begin{array}{l}\text { Higher } \\
\text { flavonoid }\end{array}$ & Cooked rice (red-white rice) & $\begin{array}{c}\text { In vivo/ } \\
50 \text { g glucose }\end{array}$ & $\begin{array}{l}47.19 \pm 11.09 \text { to } 69.74 \pm 15.59 \\
61.69 \pm 13.86 \text { to } 56.27 \pm 14.90\end{array}$ & $\approx 15$ days \\
\hline $\begin{array}{l}\text { Yulianto } \\
\text { et al./2018 [69] }\end{array}$ & Indonesia & $\begin{array}{l}\text { Adults } \\
\text { (healthy) }\end{array}$ & 12 & Lower flavonoid & $\begin{array}{l}\text { Higher } \\
\text { flavonoid }\end{array}$ & $\begin{array}{c}\text { Cooked rice (cinnamon bark, } \\
\text { pandan leaf, } \\
\text { bay leaf extract)-3 data }\end{array}$ & $\begin{array}{l}\text { In vivo/ } \\
50 \text { g glucose }\end{array}$ & $\begin{array}{c}29.00 \pm 8.65 \text { to } 32.00 \pm 8.70 \\
33.00 \pm 13.70 \text { to } 40.00 \pm 13.92 \\
31.00 \pm 8.06 \text { to } 37.00 \pm 10.69\end{array}$ & $\approx 1$ month \\
\hline $\begin{array}{l}\text { Nilsson } \\
\text { et al./2008 [70] }\end{array}$ & Swedish & $\begin{array}{l}\text { Adults } \\
\text { (healthy) }\end{array}$ & $\begin{array}{l}\text { 12/12-7 males, } \\
5 \text { females }\end{array}$ & Lower flavonoid & $\begin{array}{l}\text { Higher } \\
\text { flavonoid }\end{array}$ & $\begin{array}{l}\text { Cooked cereal (rye-wheat; } \\
\text { oat-barley)-2 data }\end{array}$ & $\begin{array}{c}\text { In vivo/ } \\
50 \text { g glucose }\end{array}$ & $\begin{array}{l}79.00 \pm 45.03 \text { to } 73.00 \pm 65.82 \\
49.00 \pm 24.25 \text { to } 85.00 \pm 45.03\end{array}$ & $\approx 28$ days \\
\hline \multicolumn{10}{|c|}{ 7. Amylose Content-GI } \\
\hline $\begin{array}{l}\text { Nounmusig } \\
\text { et al./2018 [71] }\end{array}$ & Thailand & $\begin{array}{l}\text { Adults } \\
\text { (healthy) }\end{array}$ & $\begin{array}{c}22 \\
22 / 9\end{array}$ & $\begin{array}{l}\text { Low amylose } \\
\text { rice }\end{array}$ & $\begin{array}{l}\text { Medium-high } \\
\text { amylose rice }\end{array}$ & Cooked rice/White rice & $\begin{array}{l}\text { In vivo/ } \\
50 \text { g glucose }\end{array}$ & $\begin{array}{l}90.70 \pm 36.00 \text { to } 66.10 \pm 33.00 \\
90.70 \pm 36.00 \text { to } 63.80 \pm 37.50 \\
90.70 \pm 36.00 \text { to } 66.20 \pm 24.00 \\
90.70 \pm 36.00 \text { to } 54.60 \pm 19.50 \\
90.70 \pm 36.00 \text { to } 48.10 \pm 18.60\end{array}$ & 3 weeks \\
\hline $\begin{array}{l}\text { Trinidad } \\
\text { et al./2014 [72] }\end{array}$ & Philippines & $\begin{array}{l}\text { Adults } \\
\text { (healthy) }\end{array}$ & $\begin{array}{c}12 \\
12 / 12\end{array}$ & $\begin{array}{l}\text { Low amylose } \\
\text { rice }\end{array}$ & $\begin{array}{l}\text { Medium-high } \\
\text { amylose rice }\end{array}$ & $\begin{array}{l}\text { Cooked rice/White rice-milled ( } 3 \\
\text { data) and brown rice ( } 3 \text { data) }\end{array}$ & $\begin{array}{l}\text { In vivo/ } \\
50 \text { g glucose }\end{array}$ & $\begin{array}{l}69.00 \pm 13.86 \text { to } 59.00 \pm 10.39 \\
85.00 \pm 10.39 \text { to } 59.00 \pm 10.39 \\
94.00 \pm 17.32 \text { to } 59.00 \pm 10.39 \\
61.00 \pm 10.39 \text { to } 57.00 \pm 10.39 \\
69.00 \pm 13.86 \text { to } 57.00 \pm 10.39 \\
77.00 \pm 17.32 \text { to } 57.00 \pm 10.39\end{array}$ & $\approx 27$ days \\
\hline $\begin{array}{l}\text { Trinidad } \\
\text { et al./2013 [8] }\end{array}$ & Philippines & $\begin{array}{l}\text { Adults } \\
\text { (healthy) }\end{array}$ & $\begin{array}{c}10 \\
10 / 10\end{array}$ & $\begin{array}{l}\text { Low amylose } \\
\text { rice }\end{array}$ & $\begin{array}{l}\text { Medium-high } \\
\text { amylose rice }\end{array}$ & $\begin{array}{l}\text { Cooked Rice/White Rice-milled ( } 3 \\
\text { data) and brown rice ( } 1 \text { data) }\end{array}$ & $\begin{array}{l}\text { In vivo/ } \\
50 \text { g glucose }\end{array}$ & $\begin{array}{c}59.00 \pm 12.65 \text { to } 50.00 \pm 9.49 \\
75.00 \pm 12.65 \text { to } 63.00 \pm 9.49 \\
70.00 \pm 12.65 \text { to } 57.00 \pm 9.49 \\
55.00 \pm 6.32 \text { to } 51.00 \pm 3.16\end{array}$ & $\approx 1$ month \\
\hline
\end{tabular}


Table 3. Cont.

\begin{tabular}{|c|c|c|c|c|c|c|c|c|c|}
\hline Author/Year & Country & Population & $\begin{array}{c}\text { No. of Pa- } \\
\text { tient/Replicates }\end{array}$ & Intervention & Control & Sample/Type & $\begin{array}{c}\text { Method/Reference } \\
\text { Food }\end{array}$ & $\begin{array}{l}\text { GI Value }(\mathrm{M} \pm \mathrm{SD}) \\
\text { Intervention/Control }\end{array}$ & Follow Up \\
\hline \multicolumn{10}{|c|}{ Lower-Higher Category RS [Selected low GI Carbohydrate] } \\
\hline \multicolumn{10}{|c|}{1 . Tubers Category } \\
\hline $\begin{array}{l}\text { Ek et al./ } \\
2013[45]\end{array}$ & Australia & $\begin{array}{l}\text { Adults } \\
\text { (healthy) }\end{array}$ & 10 & Lower RS & Higher RS & Potato & $\begin{array}{c}\text { In vivo/ } \\
50 \text { mg glucose }\end{array}$ & $82.00 \pm 9.49$ to $93.00 \pm 31.62$ & $12-20$ days \\
\hline $\begin{array}{l}\text { Sari et al./ } \\
2013[73]\end{array}$ & Indonesia & $\begin{array}{c}\text { Rats Wistar } \\
200-220 \mathrm{~g} \\
\text { age } \\
2-3 \text { months }\end{array}$ & 4 & Lower RS & Higher RS & Underutilized tubers & $\begin{array}{c}\text { In vivo/ } \\
50 \text { g glucose }\end{array}$ & $22.40 \pm 0.00$ to $20.60 \pm 0.49$ & $\approx 12$ days \\
\hline \multicolumn{10}{|c|}{ 2. Fruits Category } \\
\hline $\begin{array}{c}\text { Hettiaratchi } \\
\text { et al./2011 [56] }\end{array}$ & Sri Lanka & $\begin{array}{l}\text { Adults } \\
\text { (healthy) }\end{array}$ & 10 & $\begin{array}{l}\text { Lower dietary } \\
\text { fibre }\end{array}$ & $\begin{array}{l}\text { Higher dietary } \\
\text { fibre }\end{array}$ & Banana & $\begin{array}{c}\text { In vivo/ } \\
50 \mathrm{~g} \text { white bread }\end{array}$ & $67.00 \pm 22.14$ to $69.00 \pm 28.46$ & $\approx 15$ days \\
\hline
\end{tabular}

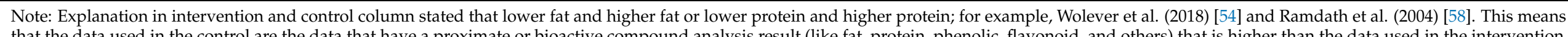

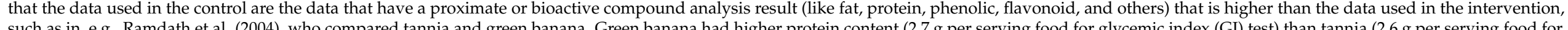

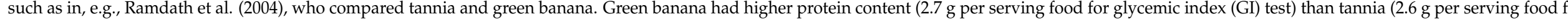

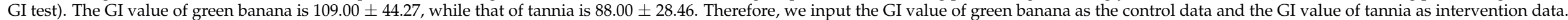


4. In vivo study- $50 \mathrm{~g}$ glucose as reference food Hidayat et al. (2017) [46]-analogue rice Bahado-Singh et al. (2011) [47]-sweet potato boiled Bahado-Singh et al. (2011) [47]- sweet potato fried Bahado-Singh et al. (2011) [47]- sweet potato baked Bahado-Singh et al. (2011) [47]- sweet potato roasted Darandakumbura et al. (2013) [14]-cultivar of rice Darandakumbura et al. (2013) [14]-method cooking of rice Darandakumbura et al. (2013) [14]-parboiled rice Subtotal $(1-$ squared $=62.43 \%, p=0.072)$

3. In vivo study-25 g glucose as reference food Ek et al. (2013) [45]-cultivar of potato

2. In vivo study-50 $\mathrm{g}$ white bread as reference food Srikaeo and Sangkhiaw (2014) [11]-rice noodles

\section{In vitro study}

Kumar et al. (2018) [23]-cultivar of rice Thiranusornkij et al. (2019) [12]-pigmented rice Odenigbo et al. (2012) [24]-cultivar of sweet potato Kumar et al. (2019) [10]-rice with normal light Kumar et al. (2019) [10]-rice with low light Srikaeo and Sangkhiaw (2014) [11]-rice noodles Sayago-Ayerdi et al. (2005) [13]-bean Sayago-Ayerdi et al. (2005) [13]-tortilla Sayago-Ayerdi et al. (2005) [13]-mixed tortilla-bean Subtotal $(1-\text { squared }=84.23 \%, p<0.001)^{*}$

Overall (1-squared $=87.19 \%, p<0.001)^{*}$

Overall in vivo studv point $1.2 \& 3(1 \text {-sauared }=86.25 \%, \mathrm{p}=0.003)^{*}$-sensitivitv 1 Overall in vivo study point $1 \& 2(1 \text {-squared }=83.36 \%, p=0.044)^{*}$-sensitivity 2 Overall in vivo study point 1 \& $3(1 \text {-squared }=87.78 \%, p=0.005)^{*}$-sensitivity 3 NOTE: Weights are from random effect analysis

Figure 4. Subgroup analysis of the glycemic index according to the differing resistant starch content in carbohydrate foods. Standardized mean difference (SMD), confidence interval (CI), and point represent the estimated overall effect size (with $95 \%$ CIs) for each study. Positive values indicate relatively higher resistant starch content in carbohydrate foods. Negative values indicate relatively lower resistant starch content in carbohydrate foods.

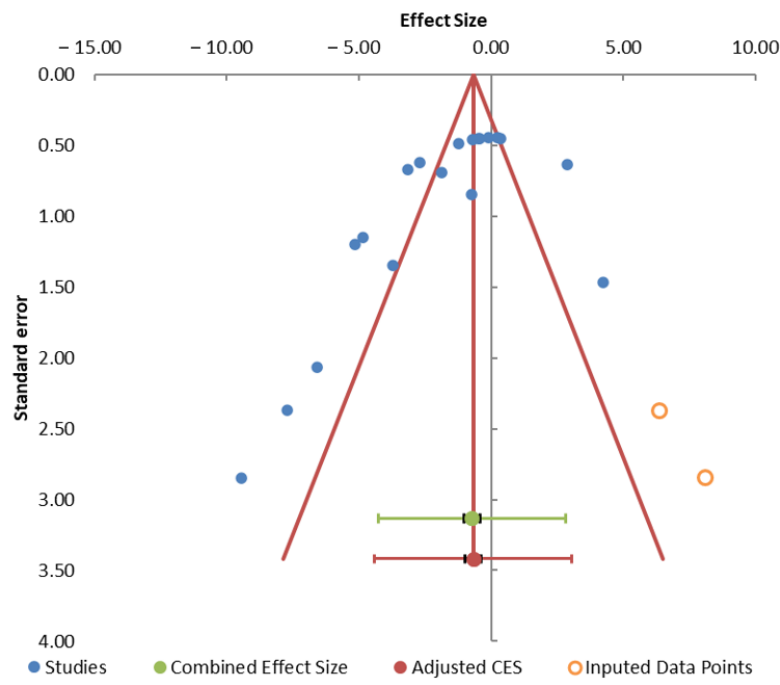

(a)

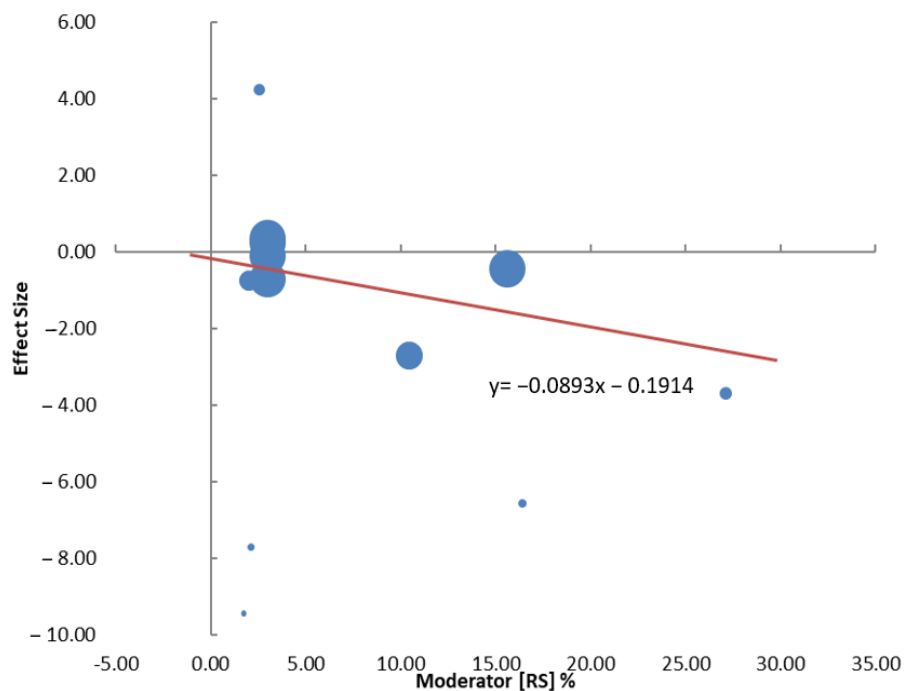

(b)

Figure 5. (a) The funnel plot of the effect of differing resistant starch content in carbohydrate foods-to-GI; (b) the metaregression between resistant starch content (\%) and effect size. 


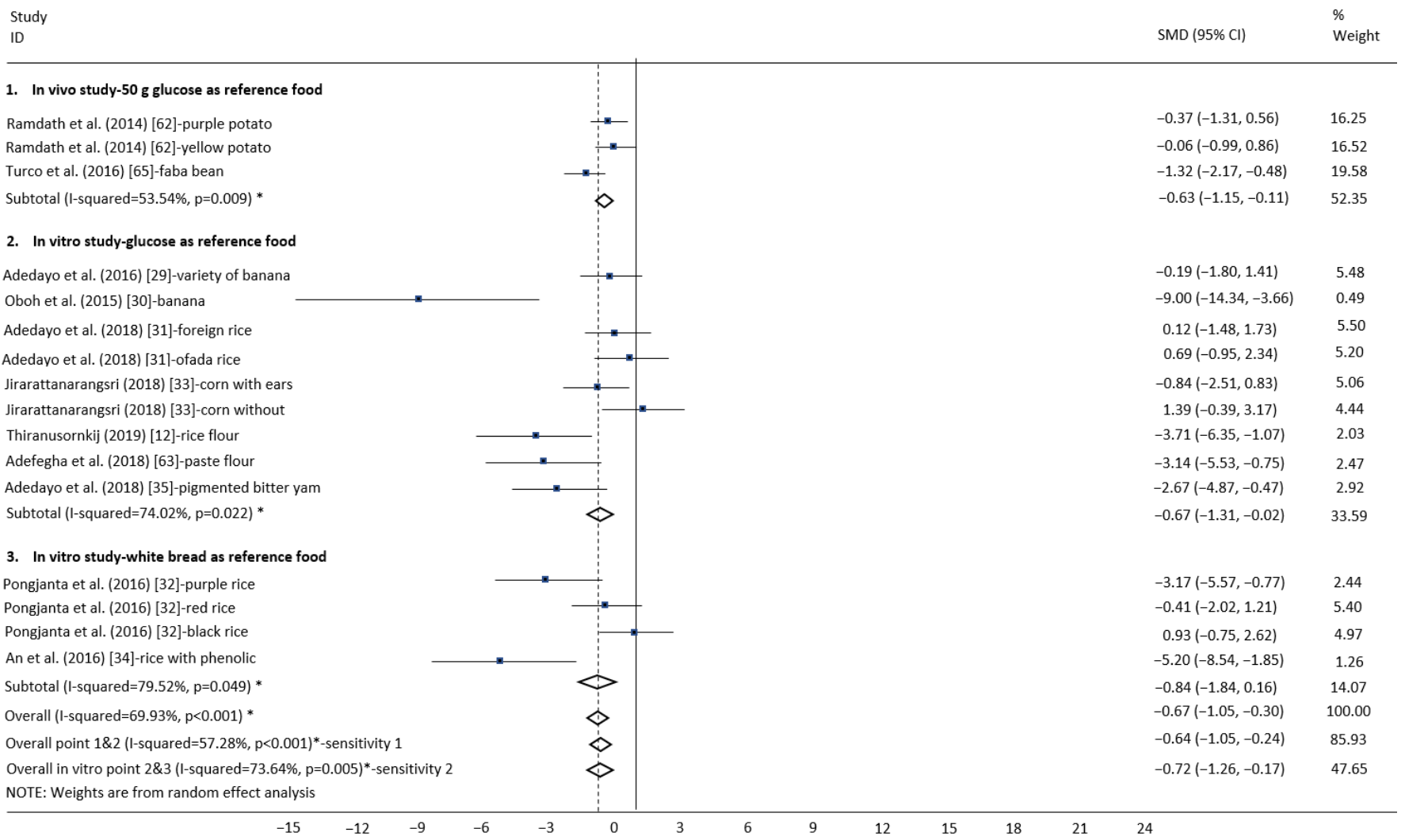

Figure 6. Subgroup analysis of the glycemic index according to the differing phenolic content in carbohydrate foods. Standardized mean difference (SMD), confidence interval (CI), and point represent the estimated overall effect size (with 95\%CIs) for each study. Positive values indicate relatively higher phenolic content in carbohydrate foods. Negative values indicate relatively lower phenolic content in carbohydrate foods.

\subsection{Strength of Evidence and Publication Bias}

The quality of evidence was evaluated by the GRADE system. The level of evidence of RS content was at level A and highly recommended. Phenol content and legume type were at level B and moderately recommended. All evidence profiles for the primary and secondary outcomes are provided in Table 5. For the meta-analysis of RS content to GI food, any publication bias was observed by Begg's test and Egger's test (Begg's, $p=0.020$; Egger's, $p=0.004$ ) (Figure 5a). For phenol content on GI food, any publication bias was observed by Begg's test and Egger's test (Begg's, $p=0.001$; Egger's, $p=0.008$ ). For the meta-analysis of legume type on GI food, any publication bias was observed by Begg's test and Egger's test (Begg's, $p=0.087 ;$ Egger's, $p=0.077$ ).

\subsection{In Vitro Laboratory Simulation Experiments}

Compared to other chemical properties, resistant starch and phenolic content significantly reduced the GI value of starchy foods (respectively, SMD: $-2.52,95 \% \mathrm{CI}:-3.29$ to -1.75 , $p<0.001$; SMD: $-0.72,95 \% \mathrm{CI}:-1.26$ to $-0.17, p=0.005$ ), with heterogeneity (respectively, $\left.\mathrm{I}^{2}=84.23 \%, p<0.001 ; \mathrm{I}^{2}=73.64 \%, p=0.005\right)$ (Table 2, Table 4, and Table 5). The lowest GI crop type is legumes (SMD: $-2.15,95 \% \mathrm{CI}$ : -3.45 to $-0.85, p<0.001$ ), with heterogeneity $\left(\mathrm{I}^{2}=72.97 \%, p<0.001\right)$ (Figure 7$)$. The heterogeneity among these studies may result from discrepancies in the population and control group. Crop species, i.e., sorghum and red kidney bean had low GI (respectively, SMD: $-0.69,95 \%$ CI: -2.33 to $0.96, p<0.001$; SMD: $-0.39,95 \% \mathrm{CI}:-2.37$ to $1.59, p=0.001$ ), with heterogeneity (respectively, $\mathrm{I}^{2}=81.4 \%$, $p<0.001 ; \mathrm{I}^{2}=73.0 \%, p=0.001$ ) (Table 5 and Figure 7). 


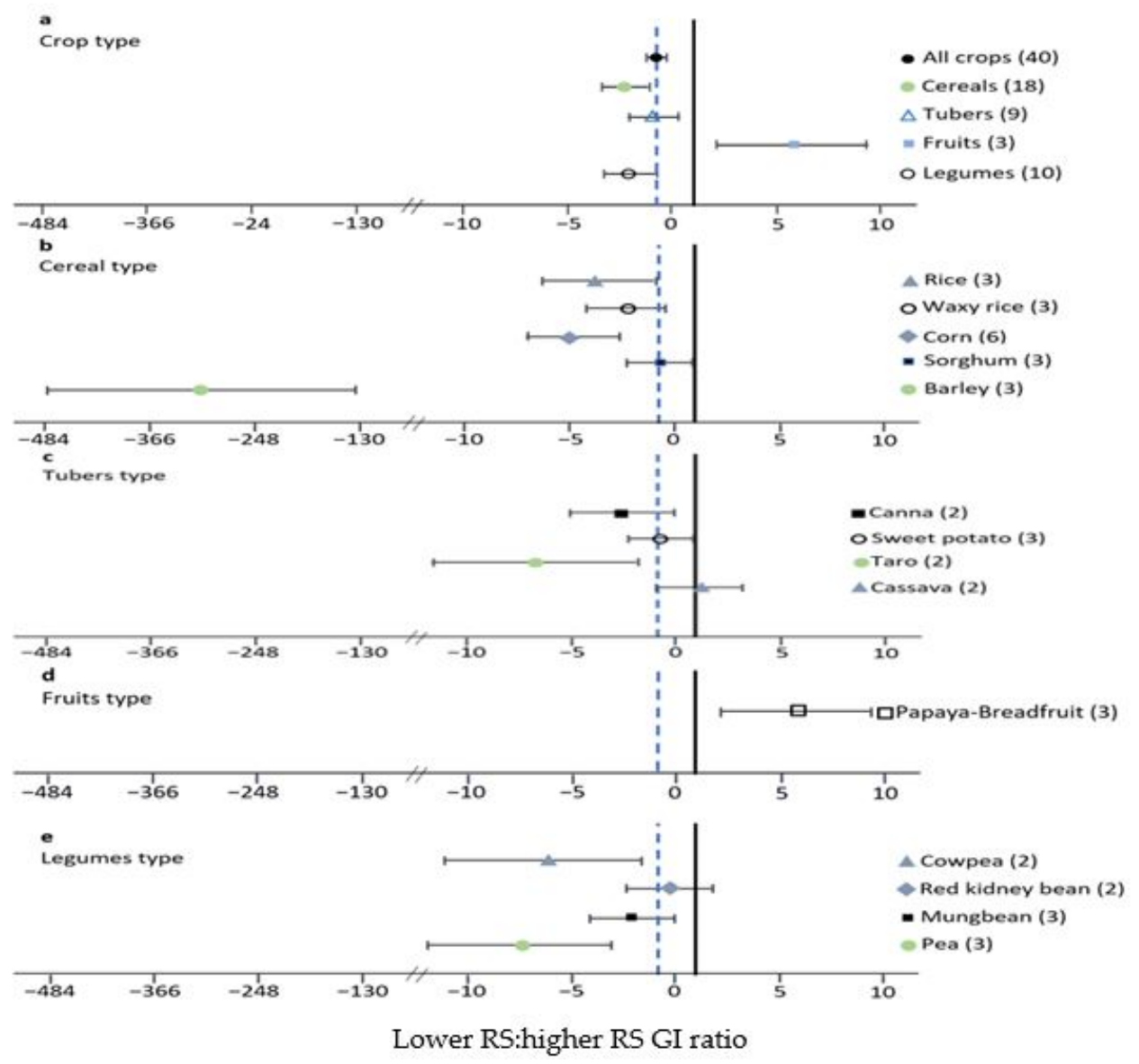

Figure 7. Influence of different crop type (a), cereal type (b), tuber type (c), fruit type (d), and legume type (e) on lower-RS to higher-RS glycemic index ratio in in vitro studies. Forest plot of cumulative effect size and 95\% confidence interval (CI) of different crop types comparing lower RS and higher RS on GI. Bold lines indicate the robust model. Only crop type was represented by at least seventeen observations. Values are mean effect sizes with $95 \%$ confidence intervals. The number of studies in each class is written in parentheses. The dotted line shows the cumulative effect size across all classes.

Table 4. Chemical properties of starchy foods determined to affect the GI in in vitro studies.

\begin{tabular}{ccccccccc}
\hline No. & Chemical Properties & $\boldsymbol{n}$ & $\mathbf{I}^{\mathbf{2}}$ & $\boldsymbol{p}$-Value & $\begin{array}{c}\text { Significancy One } \\
\text { Tailed } \boldsymbol{\alpha} \mathbf{5} \%\end{array}$ & $\mathbf{d}+\begin{array}{c}\mathbf{\%}(\boldsymbol{\Delta} \text { to } \mathbf{1} \\
\text { Value) }\end{array}$ & $\begin{array}{c}\text { Determinant } \\
\text { Order }\end{array}$ \\
\hline 1 & RS content & 9 & 84.23 & $<0.001$ & significant & -2.52 & 352 & 1 \\
2 & Dietary fibre content & 3 & 91.20 & 0.348 & not significant & -0.37 & 137 & 9 \\
3 & Fat content & 3 & 86.39 & 0.078 & not significant & 0.91 & 6 & 3 \\
4 & Protein content & 3 & 90.80 & 0.251 & not significant & -0.51 & 151 & 172 \\
5 & Phenolic content & 13 & 73.64 & 0.005 & significant & -0.72 & 2 \\
6 & Flavonoid content & 3 & 71.74 & 0.309 & not significant & -0.26 & 126 & 5 \\
\hline
\end{tabular}

\subsection{In Vivo Experiments}

In all in vivo studies, compared to other chemical properties, flavonoid and phenolic content significantly reduced the GI value of starchy foods (respectively, SMD: -0.67 , 95\%CI: -0.87 to $-0.47, p<0.001$; SMD: $-0.63,95 \% \mathrm{CI}:-1.15$ to $-0.11, p=0.009)$, with heterogeneity (respectively, $\mathrm{I}^{2}=97.34 \% ; \mathrm{I}^{2}=53.54 \%$ ) (Table 3, Table 6, and Table 7 ). In in vivo studies with $50 \mathrm{~g}$ glucose as the reference food, compared to other chemical properties, phenolic and flavonoid content significantly reduced the GI value of starchy foods (respectively, SMD: $-0.63,95 \% \mathrm{CI}:-1.15$ to $-0.11, p=0.009$; SMD: $-0.42,95 \% \mathrm{CI}:-0.72$ to -0.12 , $p=0.003$ ), with heterogeneity (respectively, $\mathrm{I}^{2}=53.54 \% ; \mathrm{I}^{2}=87.50 \%$ ) (Table 6). The lowest GI crop type is fruit (banana) (SMD: $-0.07,95 \% C I:-0.95$ to $0.80, p=0.433$ ) (Tables 3 and 7 ). 
Table 5. Selected low-GI carbohydrate foods using meta-analysis in in vitro studies.

\begin{tabular}{|c|c|c|c|c|c|c|c|c|c|}
\hline No. & Item & $n$ & $I^{2}(\%)$ & $p$-Value & $\begin{array}{l}\text { Significancy One } \\
\text { Tailed } \alpha 5 \%\end{array}$ & \% Weight & CI & $\begin{array}{l}\text { GI Value from } \\
\text { Study }[4,21,22]\end{array}$ & $\begin{array}{c}\text { Selected } \\
\text { Low GI Carbohydrate Foods }\end{array}$ \\
\hline \multicolumn{10}{|c|}{ Crop Type } \\
\hline \multirow{5}{*}{1} & All crops & & & & & 100.00 & 0.44 & - & - \\
\hline & Cereals & & & & & 11.67 & 1.03 & 56.44 & - \\
\hline & Tubers & 40 & 86.35 & $<0.001$ & significant & 18.58 & 0.68 & 55.97 & - \\
\hline & Fruits & & & & & 42.79 & 0.85 & 50.76 & - \\
\hline & Legumes & & & & & 26.96 & 1.30 & 41.94 & $\sqrt{ }$ \\
\hline \multicolumn{10}{|c|}{ Cereal Type } \\
\hline \multirow{5}{*}{2} & Rice & & & & & 15.13 & 2.64 & 67.9 & - \\
\hline & Waxy rice & & & & & 25.12 & 2.05 & 79 & - \\
\hline & Corn & 18 & 81.41 & $<0.001$ & significant & 20.88 & 2.25 & 48 & - \\
\hline & Sorghum & & & & & 38.87 & 1.65 & 32 & $\sqrt{ }$ \\
\hline & Barley & & & & & 0.00 & 175 & 40 & - \\
\hline \multicolumn{10}{|c|}{ Tuber Type } \\
\hline \multirow{4}{*}{3} & Canna & & & & & 18.63 & 2.64 & 19.87 & \\
\hline & $\begin{array}{l}\text { Sweet } \\
\text { potato }\end{array}$ & 9 & 51.59 & 0.076 & not significant & 47.45 & 1.66 & 70 & - \\
\hline & Taro & & & & & 5.24 & 4.99 & 63.1 & \\
\hline & Cassava & & & & & 28.68 & 2.13 & 78.7 & \\
\hline \multicolumn{10}{|c|}{ Fruit Type } \\
\hline 4 & $\begin{array}{l}\text { Papaya- } \\
\text { Breadfruit }\end{array}$ & 3 & - & $<0.001$ & significant & 100.00 & 3.63 & 64.5 & - \\
\hline \multicolumn{10}{|c|}{ Legume Type } \\
\hline \multirow{4}{*}{5} & Cowpea & & & & & 7.57 & 4.71 & 41 & - \\
\hline & Red bean & 10 & 7297 & $<0001$ & sionificant & 42.84 & 1.98 & 26 & $\sqrt{ }$ \\
\hline & Mungbean & 10 & 72.91 & $<0.001$ & & 41.20 & 2.02 & 76 & - \\
\hline & Pea & & & & & 8.39 & 4.47 & 35 & - \\
\hline
\end{tabular}

Table 6. Chemical properties of starchy foods determined to affect the GI in in vivo studies with $50 \mathrm{~g}$ glucose as the reference food.

\begin{tabular}{ccccccccc}
\hline No. & Chemical properties & $\boldsymbol{n}$ & \multirow{2}{*}{$\mathbf{I}^{\mathbf{2}}$} & $\boldsymbol{p}$ Value & $\begin{array}{c}\text { Significancy One } \\
\text { Tailed } \boldsymbol{\alpha} \mathbf{5} \%\end{array}$ & $\mathbf{d}+\begin{array}{c}\mathbf{\%}(\boldsymbol{\Delta} \text { to } \mathbf{1} \\
\text { Value) }\end{array}$ & $\begin{array}{c}\text { Determinant } \\
\text { Order }\end{array}$ \\
\hline 1 & RS content & 8 & 62.43 & 0.072 & not significant & -0.25 & 125 & 3 \\
2 & Dietary fibre content & 8 & 89.55 & 0.041 & significant & -0.23 & 123 & 4 \\
3 & Fat content & 7 & 79.06 & 0.033 & significant & 0.23 & 77 & 6 \\
4 & Protein content & 8 & 0.00 & $<0.001$ & significant & -0.13 & 113 & 5 \\
5 & Phenolic content & 3 & 53.54 & 0.009 & significant & -0.63 & 163 & 1 \\
6 & Flavonoid content & 7 & 87.50 & 0.003 & significant & -0.42 & 142 & 2 \\
\hline
\end{tabular}

Table 7. Selected low-GI carbohydrate foods using meta-analysis in in vivo studies.

\begin{tabular}{|c|c|c|c|c|c|c|c|c|c|}
\hline No & Item & $n$ & $\begin{array}{l}I^{2} \\
(\%)\end{array}$ & $p$-Value & $\begin{array}{l}\text { Significancy One } \\
\text { Tailed } \alpha 5 \%\end{array}$ & $\%$ Weight & CI & $\begin{array}{l}\text { GI Value } \\
\text { from Study } \\
{[4,21,22]}\end{array}$ & $\begin{array}{c}\text { Selected } \\
\text { Low GI } \\
\text { Carbohydrate Foods }\end{array}$ \\
\hline \multicolumn{10}{|c|}{ Crop Type } \\
\hline \multirow{3}{*}{1} & All crops & \multirow{3}{*}{24} & \multirow{3}{*}{86.35} & \multirow{3}{*}{0.413} & \multirow{3}{*}{ not significant } & 100.00 & 0.53 & - & - \\
\hline & Tubers & & & & & 61.35 & 0.68 & 56.44 & - \\
\hline & Fruits & & & & & 38.65 & 0.85 & 50.76 & - \\
\hline \multicolumn{10}{|c|}{ Tuber Type } \\
\hline \multirow{2}{*}{2} & \multirow{2}{*}{$\begin{array}{c}\text { Potato } \\
\text { Underutilized tuber }\end{array}$} & \multirow{2}{*}{14} & \multirow{2}{*}{59.76} & \multirow{2}{*}{0.440} & \multirow{2}{*}{ not significant } & 89.56 & 0.89 & 82 & - \\
\hline & & & & & & 10.44 & 2.60 & - & - \\
\hline \multicolumn{10}{|c|}{ Fruit Type } \\
\hline 3 & Banana & 10 & - & 0.433 & not significant & 100.00 & 0.88 & 52.78 & - \\
\hline
\end{tabular}




\section{Discussion}

\subsection{Relationship between Food Chemical Properties and GI}

This work systematically reviewed the current accessible literature and found that, in general, among the various chemical properties, the presence of resistant starch and phenolic compounds exerted significant impacts on the GI of starchy foods. It is noteworthy that evidence of this finding was consistent with the previous study. Moreover, some chemical properties show an essential impact on the GI beyond those mentioned, i.e., flavonoid, protein, dietary fibre, and amylose, which were negatively correlated with GI. Further, we found that the crop type with the lowest GI value was legumes. Subgroup analysis revealed that significant low-GI crop species were sorghum and red kidney bean, while the subgroup analysis was restricted to trials that compared some crop species. This may relate to a larger quantity of RS and phenolic compounds in the crop species.

No meta-analysis has been conducted on the effect of resistant starch levels on starchy food's GI. Previous researchers stated that the relationship between resistant starch levels and GI is a negative correlation [19]. Resistant starch is starch that cannot be digested by the small intestine within 120 min after consumption but that the large intestine can ferment. Resistant starch is a linear molecule of $\alpha-1,4$-D-glucan, which is obtained mainly from the retrogradation of the amylose fraction and has a relatively low molecular weight $\left(1.2 \times 10^{5} \mathrm{Da}\right)$ [74]. The results of a previous meta-analysis showed that resistant starch can reduce blood sugar levels and fasting insulin [9]. The same thing can be seen from the results of the meta-regression between resistant starch levels and effect size (Figure $5 b$ ), which has a negative slope (-0.09). The mechanism for decreasing GI is that resistant starch cannot be digested by digestive enzymes due to its compact molecular structure, such that there is no increase in blood sugar levels [74].

Furthermore, meta-analysis has not been conducted on the effect of dietary fibre levels on starchy foods' GI. Previous researchers stated that the relationship between dietary fibre levels and GI is negatively correlated [6,35]. The same thing can be seen from the result of the meta-regression between dietary fibre content and effect size, which has a negative slope equal to -0.11 . The mechanism of action of dietary fibre to reduce GI is by slowing down the rate of digestion of starch and increasing the duration of intestinal transit so that dietary fibre serves as a physical barrier in digestion in the intestine, thus slowing down the interaction between enzymes and substrates. In addition, the degree of viscosity of the dietary fibre is positively related to the extent of the flattening of the postprandial glucose response [75].

Meta-analysis of the effect of fat content on starchy foods' GI has not been carried out. Previous researchers stated that the relationship of fat content to GI is negatively correlated [76]. The same thing can be seen from the results of the meta-regression between fat content and effect size, which has a negative slope as much as -0.07 . The mechanism of GI reduction is that fat slows the rate at which the stomach empties, creates a steric hindrance for the enzyme [77], and interacts with amylose to form a very strong matrix, named amylo-lipid, which digestive enzymes have trouble digesting [75].

In addition, meta-analysis of the effect of protein levels on starchy foods' GI has not been done. Previous researchers stated that the relationship between protein levels and GI is negatively correlated [55]. The mechanism for decreasing GI is that a protein allegedly stimulates insulin secretion so that blood glucose is not excessive and is under control [78]. However, the meta-regression outcome between protein levels and effect size shows a different result, which has a positive slope of 0.02 .

No meta-analysis has been conducted on the effect of phenol levels on starchy foods' GI. Previous researchers stated that the relationship between phenol levels and GI is negatively correlated [79]. The same can be seen from the result of the meta-regression between phenol levels and effect size, which has a negative slope, as much as -0.0001 . The mechanism of GI reduction is that phenol inhibits the $\alpha$-amylase enzyme and the $\alpha$-glucosidase enzyme [80]. 
No meta-analysis has been conducted on the effect of flavonoid levels on starchy foods' GI. Previous researchers stated that the relationship between flavonoid levels and GI is negatively correlated [66]. The same can be seen from the result of the meta-regression between fat content and effect size, which has a negative slope, as much as -0.0002 . The mechanism of GI reduction is that flavonoids inhibit the $\alpha$-amylase and $\alpha$-glucosidase enzymes [80].

\subsection{Comparability of In Vitro Results to Forecast In Vivo Correlations to Chemical Properties and GI}

This study used both the in vivo and in vitro methods. This consideration was based on previous studies in which in vitro test results had the same trend as in vivo tests, though in vitro tests tended to have absolute values (overestimation) about 5-25 higher than those of in vivo tests $[11,81,82]$. That gap was strengthened by the results of the absolute value of SMD chemical properties towards the GI of food, which, in vitro, has a higher value compared to in vivo (Tables 4 and 6). Other considerations are several theories stating that at least 10 studies must be carried out in a meta-analysis. In the analysis, subgroup analysis and sensitivity analysis are performed. Subgroup analysis was performed based on the variable type of study and reference food. This can provide an overview of two aspects if both methods are used and if only the in vivo method with $50 \mathrm{~g}$ glucose reference food os used (Table 6). For in vivo tests, we used and compared only those using 50 g glucose reference food. This is done because the results show that if the reference food is $50 \mathrm{~g}$ of white bread or white rice, it is necessary to first convert the GI value with multiplier factors, respectively, 0.77 and 0.69 [83]. If the reference food used is $25 \mathrm{~g}$ glucose, different results would be obtained, which would need to be multiplied by 0.67 as a conversion factor [84].

For in vivo food model simulation, we suggest some recommendations. First, our study found that RS and phenolic content had positive effects on the reduction of the GI value of starchy foods. Such a correlation is stable and reliable. Thus, RS and phenolic content should be recommended for the chemical properties of starchy foods determined to affect the GI value. Second, to date, little attention has been paid to the study of the chemical properties determinant that affects the glycemic index of starchy foods and selected low-GI carbohydrates using meta-analysis. The determinant factor discussed in this study can be a meaningful direction for further research. Finally, comprehensive in vivo trials are warranted to validate [17] the positive impact of these findings.

\subsection{Determinant of Chemical Properties Affecting the GI and Low-GI Carbohydrate Foods}

In our study, the determinant effect of RS or phenolic content on GI and legume, as the selected low-GI carbohydrate food, was in accordance with the previous meta-analysis [9]. Nevertheless, differences between our study and the previous analysis should be noted. First, the previous meta-analysis included thirteen trials with the involvement of 428 participants for the RS effect, while for phenolic content to GI, no meta-analysis research was found until now. However, Ramdath et al. (2014) [62] asserted that there was a significant inverse correlation between polyphenol content and the GI of potatoes $(\mathrm{r}=-0.825$; $p<0.05 ; n=4)$. In the case of the relation between legume and GI, the previous study using meta-analysis included forty trials totaling 253 participants. We included ninety-eight trials, and added subgroup analysis based on chemical properties and the source of starchy foods according to the control group, enabling us to reach a more robust conclusion by eliminating interference factors. Our meta-analysis found that heterogeneity among trials was due mainly to the design of different control group, rather than population. In addition, we assessed the quality of the evidence and the strength of the recommendations. Thus, our work was the latest and most comprehensive one.

Low-GI foods, such as legumes, had the lowest GI compared to other carbohydrate foods because legumes have relatively higher levels of resistant starch and bioactive compounds. Beans' resistant starch levels were $24.7 \%$ [74]. In the cereal group, red sorghum had the lowest GI (Table 5), apparently due to the higher content of bioactive compounds and resistant starch compared to other cereal groups. Red sorghum's resistant starch levels 
ranged from 3.34 to $65.36 \mathrm{~g} / 100 \mathrm{~g}$ [85]. The phenol compound contained in sorghum is $445-2850 \mu \mathrm{g} / \mathrm{g}$ [86]. In the legumes, red beans had the lowest GI (Table 5), presumably due to the higher content of bioactive compounds and resistant starch compared to other legumes. The resistant starch content of red bean starch is $21.27 \%$ [87], while the total phenol content can reach $4871 \mathrm{mg}$ gallic acid equivalents (GAE)/100 g dry weight [88]. Previous studies [89] only determined the glycemic index of various staple carbohydrate-rich foods in the UK diet in five groups, such as breakfast cereals, breads, pastas, and potatoes using ten subjects.

Our study also has limitations. Though this meta-analysis includes high-quality studies, the sample sizes are small. Additionally, there is enough heterogeneity among studies, which could alter the reliability of the results. Trials with higher-quality samples and larger sample sizes are required to confirm the current results.

\subsection{Critical Review GI as Indicator for Classifying Healthy Foods and the Alternative Concept}

Although the concept of GI is widely used in explaining the causes of diabetes, some scientists consider that GI is not accurate enough to explain this. The concept of GI is considered inappropriate to classify a food as healthy or not or to describe its impact on human health. Several aspects of criticism of the GI concept include reproducibility, its impact on physiological effects, and levels and standards of the reference food used [90]. Therefore, it is necessary to use other indicators related to the character of carbohydrates besides digestibility, such as the types of food fibre found in foodstuffs and the levels of bioactive compounds contained therein [91]. Substitutes for the concept of GI proposed by health nutrition researchers include a new method for classifying starch digestion by modeling amylolysis of plant foods using first-order enzyme kinetic principles. This research opens new horizons and supports the relationship between levels of resistant starch, dietary fibre, phenolic, flavonoids, and the value of food GI.

The results evidenced that resistant starch and phenolic content reduce the GI value of starchy foods. As regards in vitro studies, it is well known that resistant starch is negatively correlated to GI, but the results obtained for the phenolic content in this systematic review were not obvious, even though part of phenolics were bound to fibre compounds known to reduce the digestion in the flattening of postprandial glucose response. Moreover, phenols inhibit the $\alpha$-amylase and $\alpha$-glucosidase enzymes. Among cereals, sorghum-a gluten free cereal-is the only one that reveals high-resistant starch and low GI. This is a very interesting result due to the fact that gluten-free foods generally are low in fibre and high in GI. This finding could be useful to investigate the potential of sorghum as gluten-free products.

\section{Conclusions}

The present work successfully elucidated that resistant starch, phenolic, flavonoid, protein, and dietary fibre content exerted crucial roles in reducing the glycemic index of starchy foods. Among the starchy foods, sorghum and red kidney bean were identified to have low-GI properties. Sorghum and kidney beans have a low GI because both contain relatively high resistant starch and phenolic compounds. The relationship between levels of resistant starch, phenolic, flavonoids, protein, and fibre to GI was a negatively correlation. Resistant starch causes steric hindrance in the molecular structure of the starch, while phenolic compounds (including flavonoids) are capable of inhibiting the $\alpha$-amylase and $\alpha$-glucosidase enzymes. The mode of action of resistant starch in reducing GI is making the enzyme unable to hydrolyze and disrupting the hydrolysis on non-resistant starch (which creates steric hindrance). Nevertheless, microbes ferment the resistant starch in the colon so that the body will not absorb it as glucose. Protein is supposed to stimulate the secretion of insulin so that blood glucose is not excessive and can be controlled. The fibre functions as an inhibitor of physical digestion in the intestine, thereby slowing down the interactions between enzymes with the substrates. 
Author Contributions: Conceptualization-F.A.A., C.H.W., D.N.F., N.E.S., and A.J.; Formal analysisF.A.A., C.H.W., D.N.F., N.E.S., and A.J.; Data curation-F.A.A., C.H.W., D.N.F., N.E.S., and A.J.; Investigation-F.A.A., C.H.W., D.N.F., N.E.S., and A.J.; Methodology- F.A.A., D.N.F., and A.J.; Supervision-C.H.W., D.N.F., N.E.S., and A.J.; Validation-D.N.F., C.H.W., D.N.F., N.E.S., and A.J.; Visualization-F.A.A., C.H.W., D.N.F., N.E.S. and A.J.; Writing-original draft, F.A.A., C.H.W., D.N.F., N.E.S., and A.J.; Project administration- F.A.A. and D.N.F.; Resources- F.A.A., C.H.W., D.N.F., N.E.S. and A.J.; Writing-review \& editing, F.A.A., C.H.W., D.N.F., N.E.S. and A.J. All authors have read and agreed to the published version of the manuscript.

Funding: This research received no external funding.

Institutional Review Board Statement: Not applicable.

Informed Consent Statement: Not applicable.

Data Availability Statement: Not applicable.

Acknowledgments: The authors are grateful to DPIS (Direktorat Publikasi Ilmiah dan Informasi Strategis), IPB University for providing technical support during the writing of this manuscript.

Conflicts of Interest: The authors declare no conflict of interest.

\section{References}

1. Venn, B.J.; Green, T.J. Glycemic index and glycemic load: Measurement issues and their effect on diet-disease relationships. Eur. J. Clin. Nutr. 2007, 61, S122-S131. [CrossRef]

2. ISO. International Standard International Standard; The International Organization for Standardization: Geneva, Switzerland, 2010; Volume 26642:2010, ISBN 2831886376.

3. Diederichs, T.; Herder, C.; Roßbach, S.; Roden, M.; Wudy, S.A.; Nöthlings, U.; Alexy, U.; Buyken, A.E. Carbohydrates from sources with a higher glycemic index during adolescence: Is evening rather than morning intake relevant for risk markers of type 2 diabetes in young adulthood? Nutrients 2017, 9, 591. [CrossRef]

4. Thompson, S.V.; Winham, D.M.; Hutchins, A.M. Bean and rice meals reduce postprandial glycemic response in adults with type 2 diabetes: A cross-over study. Nutr. J. 2012, 11, 1. [CrossRef]

5. Giri, S.; Banerji, A.; Lele, S.S.; Ananthanarayan, L. Starch digestibility and glycaemic index of selected Indian traditional foods: Effects of added ingredients. Int. J. Food Prop. 2017, 20, S290-S305. [CrossRef]

6. Jenkins, D.J.A.; Kendall, C.W.C.; Augustin, L.S.A.; Mitchell, S.; Sahye-Pudaruth, S.; Blanco Mejia, S.; Chiavaroli, L.; Mirrahimi, A.; Ireland, C.; Bashyam, B.; et al. Effect of legumes as part of a low glycemic index diet on glycemic control and cardiovascular risk factors in type 2 diabetes mellitus: A randomized controlled trial. Arch. Intern. Med. 2012, 172, 1653-1660. [CrossRef] [PubMed]

7. Omage, K.; Omage, S.O. Evaluation of the glycemic indices of three commonly eaten mixed meals in Okada, Edo State. Food Sci. Nutr. 2018, 6, 220-228. [CrossRef]

8. Trinidad, T.P.; Mallillin, A.C.; Encabo, R.R.; Sagum, R.S.; Felix, A.D.; Juliano, B.O. The effect of apparent amylose content and dietary fibre on the glycemic response of different varieties of cooked milled and brown rice. Int. J. Food Sci. Nutr. 2013, 64, 89-93. [CrossRef] [PubMed]

9. Wang, Y.; Chen, J.; Song, Y.H.; Zhao, R.; Xia, L.; Chen, Y.; Cui, Y.P.; Rao, Z.Y.; Zhou, Y.; Zhuang, W.; et al. Effects of the resistant starch on glucose, insulin, insulin resistance, and lipid parameters in overweight or obese adults: A systematic review and meta-analysis. Nutr. Diabetes 2019, 9, 1-11. [CrossRef] [PubMed]

10. Kumar, A.; Panda, D.; Biswal, M.; Dey, P.; Behera, L.; Baig, M.J.; Nayak, L.; Ngangkham, U.; Sharma, S. Low Light Stress Influences Resistant Starch Content and Glycemic Index of Rice (O. sativa L). Starch Staerke 2019, 71. [CrossRef]

11. Srikaeo, K.; Sangkhiaw, J. Effects of amylose and resistant starch on glycaemic index of rice noodles. LWT Food Sci. Technol. 2014, 59, 1129-1135. [CrossRef]

12. Thiranusornkij, L.; Thamnarathip, P.; Chandrachai, A.; Kuakpetoon, D.; Adisakwattana, S. Comparative studies on physicochemical properties, starch hydrolysis, predicted glycemic index of Hom Mali rice and Riceberry rice flour and their applications in bread. Food Chem. 2019, 283, 224-231. [CrossRef] [PubMed]

13. Sáyago-Ayerdi, S.G.; Tovar, J.; Osorio-Díaz, P.; Paredes-López, O.; Bello-Pérez, L.A. In vitro starch digestibility and predicted glycemic index of corn tortilla, black beans, and tortilla-bean mixture: Effect of cold storage. J. Agric. Food Chem. 2005, 53, 1281-1285. [CrossRef] [PubMed]

14. Darandakumbura, H.D.K.; Wijesinghe, D.G.N.G.; Rohitha Prasantha, B.D. Sri Lanka Effect of Processing Conditions and Cooking Methods on Resistant Starch, Dietary Fibre and Glycemic Index of Rice. Trop. Agric. Res. 2013, 24, $163-174$.

15. Borenstein, M.; Hedges, L.V.; Higgins, J.P.T.; Rothstein, H.R. Fixed-Effect Versus Random-Effects Models. In Introduction to Meta-Analysis; John Wiley \& Sons Ltd.: Hoboken, NJ, USA, 2009; pp. 77-86.

16. Viswanathan, M.; Ansari, M.T.; Berkman, N.D.; Chang, S.; Hartling, L.; McPheeters, M.; Santaguida, P.L.; Shamliyan, T.; Singh, K.; Tsertsvadze, A.; et al. Assessing the Risk of Bias of Individual Studies in Systematic Reviews of Health Care Interventions; Agency for Healthcare Research and Quality: Rockville, MD, USA, 2012. 
17. Fu, S.; Li, L.; Deng, S.; Zan, L.; Liu, Z. Effectiveness of advanced carbohydrate counting in type 1 diabetes mellitus: A systematic review and meta-analysis. Sci. Rep. 2016, 6, 1-8. [CrossRef]

18. Guyatt, G.H. Guyatt 2008-What is "quality of evidence" and why is it important to clinicians. BMJ 2008, 336, 995-998. [CrossRef]

19. Goldet, G.; Howick, J. Understanding GRADE: An introduction. J. Evid. Based Med. 2013, 6, 50-54. [CrossRef]

20. Guyatt, G.H.; Oxman, A.D.; Vist, G.E.; Kunz, R.; Falck-Ytter, Y.; Alonso-Coello, P.; Schünemann, H.J. GRADE: An emerging consensus on rating quality of evidence and strength of recommendations. Chin. J. Evid. Based Med. 2009, 9, 8-11. [CrossRef]

21. Prasad, M.P.R.; Rao, B.D.; Kalpana, K.; Rao, M.V.; Patil, J.V. Glycaemic index and glycaemic load of sorghum products. J. Sci. Food Agric. 2015, 95, 1626-1630. [CrossRef]

22. Chandrasekara, A.; Josheph Kumar, T. Roots and tuber crops as functional foods: A review on phytochemical constituents and their potential health benefits. Int. J. Food Sci. 2016, 2016. [CrossRef] [PubMed]

23. Kumar, A.; Sahoo, U.; Baisakha, B.; Okpani, O.A.; Ngangkham, U.; Parameswaran, C.; Basak, N.; Kumar, G.; Sharma, S.G. Resistant starch could be decisive in determining the glycemic index of rice cultivars. J. Cereal Sci. 2018, 79, 348-353. [CrossRef]

24. Odenigbo, A.; Rahimi, J.; Ngadi, M.; Amer, S.; Mustafa, A. Starch digestibility and predicted glycemic index of fried sweet potato cultivars. Funct. Foods Health Dis. 2012, 2, 280. [CrossRef]

25. Vahini, J.; Bhaskarachary, K.; Rao, M.V.V. Effect of cooking on glycemic index of commonly consumed corn in inda. Int. J. Food Nutr. Sci. 2017, 6, 25-30.

26. Kim, H.J.; White, P.J. In vitro digestion rate and estimated glycemic index of oat flours from typical and high $\beta$-glucan oat lines. J. Agric. Food Chem. 2012, 60, 5237-5242. [CrossRef]

27. Amin, T.; Naik, H.R.; Hussain, S.Z.; Mir, M.A.; Jabeen, A. In vitro digestion, physicochemical and morphological properties of low glycemic index rice flour prepared through enzymatic hydrolysis. Int. J. Food Prop. 2018, 21, 2632-2645. [CrossRef]

28. Klunklin, W.; Savage, G. Physicochemical, antioxidant properties and in vitro digestibility of wheat-purple rice flour mixtures. Int. J. Food Sci. Technol. 2018, 53, 1962-1971. [CrossRef]

29. Adedayo, B.C.; Oboh, G.; Oyeleye, S.I.; Olasehinde, T.A. Antioxidant and Antihyperglycemic Properties of Three Banana Cultivars (Musa spp.). Scientifica 2016, 2016, 1-5. [CrossRef] [PubMed]

30. Oboh, G.; Ademosun, A.O.; Akinleye, M.; Omojokun, O.S.; Boligon, A.A.; Athayde, M.L. Starch composition, glycemic indices, phenolic constituents, and antioxidative and antidiabetic properties of some common tropical fruits. J. Ethn. Foods 2015, 2, 64-73. [CrossRef]

31. Adedayo, B.C.; Adebayo, A.A.; Nwanna, E.E.; Oboh, G. Effect of cooking on glycemic index, antioxidant activities, $\alpha$-amylase, and $\alpha$-glucosidase inhibitory properties of two rice varieties. Food Sci. Nutr. 2018, 6, 2301-2307. [CrossRef] [PubMed]

32. Pongjanta, J.; Chomsri, N.-O.; Meechoui, S. Correlation of pasting behaviors with total phenolic compounds and starch digestibility of indigenous pigmented rice grown in upper Northern Thailand. Funct. Foods Health Dis. 2016, 6, 133-143. [CrossRef]

33. Jirarattanarangsri, W. The Effect of Traditional Thermal Cooking Processes on Anthocyanins, Total Phenolic Content, Antioxidant Activities and Glycemic Index in Purple Waxy Corn. Food Appl. Biosci. J. 2018, 6, 154-166.

34. An, J.S.; Bae, I.Y.; Han, S.I.; Lee, S.J.; Lee, H.G. In vitro potential of phenolic phytochemicals from black rice on starch digestibility and rheological behaviors. J. Cereal Sci. 2016, 70, 214-220. [CrossRef]

35. Adedayo, B.; Okeke, B.M.; Oyeleye, S.I.; Oboh, G. Effects of boiling on the estimated Glycemic Index (eGI) and $\alpha-$ amylase/ $\alpha-$ glucosidase inhibitory properties of two Bitter Yam (Dioscorea dumetorum) spp. Biokemistri 2018, 30, 21-31.

36. Frei, M.; Siddhuraju, P.; Becker, K. Studies on the in vitro starch digestibility and the glycemic index of six different indigenous rice cultivars from the Philippines. Food Chem. 2003, 83, 395-402. [CrossRef]

37. Lemlioglu-austin, D.; Turner, N.D.; Mcdonough, C.M. Effects of Sorghum [Sorghum bicolor (L.) Moench] Crude Extracts on Starch Digestibility, Estimated Glycemic Index (EGI), and Resistant Starch (RS) Contents of Porridges. Molecules 2012, 17, 11124-11138. [CrossRef]

38. Shen, R.; Zang, W.; Dong, J. Preparation, structural characteristics and digestibility of resistant starches from highland barley, oats and buckwheat starches. J. Food Nutr. Res. 2016, 55, 303-312.

39. Srikaeo, K.; Mingyai, S.; Sopade, P.A. Physicochemical properties, resistant starch content and enzymatic digestibility of unripe banana, edible canna, taro flours and their rice noodle products. Int. J. Food Sci. Technol. 2011, 46, 2111-2117. [CrossRef]

40. Simsek, S.; El, S.N. Production of resistant starch from taro (Colocasia esculenta L. Schott) corm and determination of its effects on health by in vitro methods. Carbohydr. Polym. 2012, 90, 1204-1209. [CrossRef]

41. Ratnaningsih, N.; Harmayani, E.; Marsono, Y. In vitro Starch Digestibility and Estimated Glycemic Index of Indonesian Cowpea Starch (Vigna unguiculata). Pak. J. Nutr. 2017, 16, 1-8. [CrossRef]

42. Chung, H.; Liu, Q.; Pauls, K.P.; Fan, M.Z.; Yada, R. In vitro starch digestibility, expected glycemic index and some physicochemical properties of starch and flour from common bean (Phaseolus vulgaris L.) varieties grown in Canada. Food Res. Int. 2008, 41, 869-875. [CrossRef]

43. Eashwarage, I.S. Dietary fibre, resistant starch and in-vitro starch digestibility of selected elevencommonly consumed legumes (Mung bean, Cowpea, Soybean and Horse Gram) in Sri Lanka. Res. J. Chem. Sci. 2017, 7, 27-33.

44. Sandhu, K.S.; Lim, S. Digestibility of legume starches as influenced by their physical and structural properties. Carbohydr. Polym. 2008, 71, 245-252. [CrossRef]

45. Ek, K.L.; Wang, S.; Copeland, L.; Brand-Miller, J.C. Discovery of a low-glycaemic index potato and relationship with starch digestion in vitro. Br. J. Nutr. 2014, 111, 699-705. [CrossRef] [PubMed] 
46. Hidayat, B.; Akmal, S.; Muslihudin, M.; Suhada, B. Assessment of Corn-Based Rice Analogues Made from Modified Corn Flour and Cassava Starch Which Processed by Granulation Method as Functional Food. Food Sci. Qual. Manag. 2017, 61, 19-24.

47. Bahado-Singh, P.S.; Riley, C.K.; Wheatley, A.O.; Lowe, H.I.C. Relationship between processing method and the glycemic indices of ten sweet potato (Ipomoea batatas) cultivars commonly consumed in Jamaica. J. Nutr. Metab. 2011, 2011. [CrossRef] [PubMed]

48. Oboh, H.A.; Ogbebor, V.O. The Effect of Processing on the Glycemic Index and Glycemic Load of Maize (Zea Mays). Biology 2010, $25,46-51$.

49. Eli-Cophie, D.; Agbenorhevi, J.K.; Annan, R.A. Glycemic index of some local staples in Ghana. Food Sci. Nutr. 2017, 5, 131-138. [CrossRef]

50. Mlotha, V.; Mwangwela, A.M.; Kasapila, W.; Siyame, E.W.P.; Masamba, K. Glycemic responses to maize flour stiff porridges prepared using local recipes in Malawi. Food Sci. Nutr. 2016, 4, 322-328. [CrossRef]

51. Shobana, S.; Kumari, S.R.U.; Malleshi, N.G.; Ali, S.Z. Glycemic response of rice, wheat and finger millet based diabetic food formulations in normoglycemic subjects. Int. J. Food Sci. Nutr. 2007, 58, 363-372. [CrossRef]

52. Cavallero, A.; Empilli, S.; Brighenti, F.; Stanca, A.M. High $(1 \rightarrow 3,1 \rightarrow 4)$ - $\beta$-glucan barley fractions in bread making and their effects on human glycemic response. J. Cereal Sci. 2002, 36, 59-66. [CrossRef]

53. Meija, L.; Havensone, G.; Lejnieks, A. Postprandial Glycaemic and Insulinaemic Responses after Consumption of Activated Wheat and Triticale Grain Flakes. J. Nutr. Metab. 2019, 2019. [CrossRef]

54. Wolever, T.M.S.; Jones, P.J.H.; Jenkins, A.L.; Mollard, R.C.; Wang, H.; Johnston, A.; Johnson, J.; Chu, Y.F. Glycaemic and insulinaemic impact of oats soaked overnight in milk vs. cream of rice with and without sugar, nuts, and seeds: A randomized, controlled trial. Eur. J. Clin. Nutr. 2019, 73, 86-93. [CrossRef] [PubMed]

55. Senavirathna, R.M.I.S.K.; Ekanayake, S.; Jansz, E.R.; Welihinda, J. Proximate composition, glycemic indices, and some factors affecting glycemic indices of underutilized tubers. Starch Staerke 2014, 66, 1041-1048. [CrossRef]

56. Hettiaratchi, U.P.K.; Ekanayake, S.; Welihinda, J. Chemical compositions and glycemic responses to banana varieties. Int. J. Food Sci. Nutr. 2011, 62, 307-309. [CrossRef]

57. Kouassi, N.K.; Tiahou, G.G.; Abodo, J.R.F.; Camara-Cisse, M.; Amani, G.N.G. Influence of the variety and cooking method on glycemic index of yam. Pak. J. Nutr. 2009, 8, 993-999. [CrossRef]

58. Ramdath, D.D.; Isaacs, R.L.C.; Teelucksingh, S.; Wolever, T.M.S. Glycaemic index of selected staples commonly eaten in the Caribbean and the effects of boiling v. crushing. Br. J. Nutr. 2004, 91, 971-977. [CrossRef] [PubMed]

59. Oboh, H.; Osagie, A.; Omotosho, A. Glycemic response of some boiled legumes commonly eaten in nigeria. Diabetol. Croat. 2010, 39, 125-131.

60. Araya, H.; Pak, N.; Vera, G.; Alviña, M. Digestion rate of legume carbohydrates and glycemic index of legume-based meals. Int. J. Food Sci. Nutr. 2003, 54, 119-126. [CrossRef]

61. Al Dhaheri, A.S.; Henry, C.J.K.; Mohamad, M.N.; Ohuma, E.O.; Ismail, L.C.; Al Meqbaali, F.T.; Jarrar, A.H. Glycaemic index and glycaemic load values of commonly consumed foods in the United Arab Emirates. Br. J. Nutr. 2017, 117, 1110-1117. [CrossRef]

62. Ramdath, D.D.; Padhi, E.; Hawke, A.; Sivaramalingam, T.; Tsao, R. The glycemic index of pigmented potatoes is related to their polyphenol content. Food Funct. 2014, 5, 909-915. [CrossRef]

63. Adefegha, S.A.; Olasehinde, T.A.; Oboh, G. Pasting Alters Glycemic Index, Antioxidant Activities, and Starch-Hydrolyzing Enzyme Inhibitory Properties of Whole Wheat Flour. Food Sci. Nutr. 2018, 6, 1591-1600. [CrossRef]

64. Shobana, S.; Kokila, A.; Lakshmipriya, N.; Subhashini, S.; Ramya Bai, M.; Mohan, V.; Malleshi, N.G.; Anjana, R.M.; Henry, C.J.K.; Sudha, V. Glycaemic Index of Three Indian Rice Varieties. Int. J. Food Sci. Nutr. 2012, 63, 178-183. [CrossRef] [PubMed]

65. Turco, I.; Bacchetti, T.; Bender, C.; Zimmermann, B.; Oboh, G.; Ferretti, G. Polyphenol Content and Glycemic Load of Pasta Enriched with Faba Bean Flour. Funct. Foods Health Dis. 2016, 6, 291. [CrossRef]

66. Abubakar, B.; Yakasai, H.M.; Zawawi, N.; Ismail, M. Compositional analyses of white, brown and germinated forms of popular Malaysian rice to offer insight into the growing diet-related diseases. J. Food Drug Anal. 2018, 26, 706-715. [CrossRef] [PubMed]

67. Raghuvanshi, R.; Dutta, A.; Tewari, G.; Suri, S. Qualitative Characteristics of Red Rice and White Rice Procured from Local Market of Uttarakhand: A Comparative Study. J. Rice Res. 2017, 10, 49-53.

68. Meera, K.; Smita, M.; Haripriya, S.; Sen, S. Varietal influence on antioxidant properties and glycemic index of pigmented and non-pigmented rice. J. Cereal Sci. 2019, 87, 202-208. [CrossRef]

69. Yulianto, W.A.; Suryani, C.L.; Susiati, A.M.; Luwihana, S. Evaluation of Chromium Fortified- Parboiled Rice Coated with Herbal Extracts: Resistant Starch and Glycemic Index. Int. Food Res. J. 2018, 25, 2608-2613.

70. Nilsson, A.C.; Östman, E.M.; Granfeldt, Y.; Björck, I.M.E. Effect of cereal test breakfasts differing in glycemic index and content of indigestible carbohydrates on daylong glucose tolerance in healthy subjects. Am. J. Clin. Nutr. 2008, 87, 645-654. [CrossRef]

71. Nounmusig, J.; Kongkachuichai, R.; Sirichakwal, P.P.; Yamborisut, U.; Charoensiri, R.; Vanavichit, A. The effect of low and high glycemic index based rice varieties in test meals on postprandial blood glucose, insulin and incretin hormones response in prediabetic subjects. Int. Food Res. J. 2018, 25, 835-841.

72. Trinidad, T.P.; Mallillin, A.C.; Sagum, R.S.; Felix, A.D.R.; Tuaño, A.P.P.; Juliano, B.O. Relative effect of apparent amylose content on the glycemic index of milled and brown rice. Philipp. Agric. Sci. 2014, 97, 405-408.

73. Sari, I.P.; Lukitaningsih, E.; Rumiyati, R.; Setiawan, I. Glycaemic Index of Uwi, Gadung, and Talas Which Were Given on Rat. Tradit. Med. J. 2013, 18, 127-131. 
74. Fuentes-Zaragoza, E.; Riquelme-Navarrete, M.J.; Sánchez-Zapata, E.; Pérez-Álvarez, J.A. Resistant starch as functional ingredient: A review. Food Res. Int. 2010, 43, 931-942. [CrossRef]

75. Jenkins, D.J.A.; Kendall, C.W.C.; Augustin, L.S.A.; Franceschi, S.; Hamidi, M.; Marchie, A.; Jenkins, A.L.; Axelsen, M. Glycemic index: Overview of implications in health and disease. Am. J. Clin. Nutr. 2002, 76, 266-273. [CrossRef]

76. Osman, N.M.H.; Mohd-Yusof, B.N.; Ismail, A. Estimating Glycemic Index of Rice-Based Mixed Meals by Using Predicted and Adjusted Formulae. Rice Sci. 2017, 24, 274-282. [CrossRef]

77. Dupuis, J.H.; Liu, Q.; Yada, R.Y. Methodologies for Increasing the Resistant Starch Content of Food Starches: A Review Compr. Rev. Food Sci. Food Saf. 2014, 13, 1219-1234. [CrossRef]

78. Dworatzek, P.D.; Arcudi, K.; Gougeon, R.; Husein, N.; Sievenpiper, J.L.; Williams, S.L. Nutrition Therapy. Can. J. Diabetes 2013, 37, S45-S55. [CrossRef]

79. Bule, M.; Abdurahman, A.; Nikfar, S.; Abdollahi, M.; Amini, M. Antidiabetic effect of quercetin: A systematic review and meta-analysis of animal studies. Food Chem. Toxicol. 2019, 125, 494-502. [CrossRef]

80. Afandi, F.; Wijaya, C.; Faridah, D.; Suyatma, N. Relationship between Carbohydrate Content and the Glycemic Index in High-Carbohydrate Foods. Pangan 2019, 28, 145-159. [CrossRef]

81. Ferrer-Mairal, A.; Peñalva-Lapuente, C.; Iglesia, I.; Urtasun, L.; De Miguel-Etayo, P.; Remón, S.; Cortés, E.; Moreno, L.A. In vitro and in vivo assessment of the glycemic index of bakery products: Influence of the reformulation of ingredients. Eur. J. Nutr. 2012, 51, 947-954. [CrossRef]

82. Fujiwara, N.; Hall, C.; Jenkins, А. ВВЕДЕНИЕ Page 1 of 23. Cereal Chem. J. 2017, 94, 110-116. [CrossRef]

83. Foster-Powell, K.; Holt, S.H.; Brand-Miller, J.C. International Table of Glycemic Index and Glycemic Load values. Am. J. Clin. Nutr. 2002, 76, 5-56. [CrossRef] [PubMed]

84. Lee, B.M.; Wolever, T.M.S. Effect of glucose, sucrose and fructose on plasma glucose and insulin responses in normal humans: Comparison with white bread. Eur. J. Clin. Nutr. 1998, 52, 924-928. [CrossRef]

85. Teixeira, N.D.C.; Queiroz, V.A.V.; Rocha, M.C.; Amorim, A.C.P.; Soares, T.O.; Monteiro, M.A.M.; De Menezes, C.B.; Schaffert, R.E.; Garcia, M.A.V.T.; Junqueira, R.G. Resistant starch content among several sorghum (Sorghum bicolor) genotypes and the effect of heat treatment on resistant starch retention in two genotypes. Food Chem. 2016, 197, 291-296. [CrossRef] [PubMed]

86. Xiong, Y.; Zhang, P.; Warner, R.D.; Fang, Z. Sorghum Grain: From Genotype, Nutrition, and Phenolic Profile to Its Health Benefits and Food Applications. Compr. Rev. Food Sci. Food Saf. 2019, 18, 2025-2046. [CrossRef] [PubMed]

87. Reddy, C.K.; Suriya, M.; Haripriya, S. Physico-chemical and functional properties of Resistant starch prepared from red kidney beans (Phaseolus vulgaris.L) starch by enzymatic method. Carbohydr. Polym. 2013, 95, 220-226. [CrossRef] [PubMed]

88. Yang, Q.Q.; Gan, R.Y.; Ge, Y.Y.; Zhang, D.; Corke, H. Polyphenols in Common Beans (Phaseolus vulgaris L.): Chemistry, Analysis, and Factors Affecting Composition. Compr. Rev. Food Sci. Food Saf. 2018, 17, 1518-1539. [CrossRef] [PubMed]

89. Anton, L.M.; Gambell, J.M.; Lee, D.M.; Bryant, S.P.; Jebb, S.A. Determination of Glycemic Index pf Various Stable Carbohydraterich Foods in the UK diet. Eur. J. Clin. Nutr. 2009, 62, 279-285.

90. Devries, J.W. Glycemic Index: The Analytical Perspective. Cereal Foods World 2007, 52, 45-49. [CrossRef]

91. Edwards, C.H.; Warren, F.J.; Milligan, P.J.; Butterworth, P.J.; Ellis, P.R. A Novel Method for Classifying Starch Digestion by Modelling the Amylolysis of Plant Foods Using First-Order Enzyme Kinetic Principles. Food Funct. 2014, 5, 2751-2758. [CrossRef] 